\title{
NMR Spectroscopic Method for Studying Homogenous Liquid Phase Reaction Kinetics in Systems Used in Reactive Gas Absorption and Application to Monoethanolamine-Water-Carbon Dioxide
}

\author{
Richard Behrens ${ }^{\mathrm{a}}$, Maximilian Dyga ${ }^{\mathrm{a}}$, Georg Sieder ${ }^{\mathrm{b}}$, Erik von Harbou ${ }^{\mathrm{a}, 1, *}$, \\ Hans Hasse ${ }^{a}$ \\ ${ }^{a}$ Laboratory of Engineering Thermodynamics (LTD), Technische Universität \\ Kaiserslautern, Erwin-Schrödinger-Straße 44, Kaiserslautern, 67663, Germany \\ ${ }^{b} B A S F$ SE RCP/CF, Ludwigshafen, 67056, Germany
}

\begin{abstract}
An NMR spectroscopic method for measuring homogenous liquid phase reaction kinetics in systems that are used in reactive gas absorption processes is presented. In the kinetic experiment, carbon dioxide loaded and unloaded aqueous amine solutions are mixed such that no gas phase is involved. This procedure enables studying liquid phase reaction kinetics without the influence of the kinetics of the physical absorption process. A rapid-mixing NMR flow cell is used for the measurements, which are carried out in stopped-flow mode. ${ }^{1} \mathrm{H}$ NMR spectra are taken at short intervals to monitor the kinetic process. The cell is liquid thermostatted and pressure resistant, such that a wide range of conditions can be studied. The new method was used for studying reaction kinetics in the system monoethanolamine (MEA)-water
\end{abstract}

\footnotetext{
*Corresponding author

Email address: erik.vonharbou@mv.uni-kl.de (Erik von Harbou)

${ }^{1}$ Current affiliation: BASF SE RCP/CG, Ludwigshafen, 67056, Germany
} 
$\left(\mathrm{H}_{2} \mathrm{O}\right)$-carbon dioxide $\left(\mathrm{CO}_{2}\right)$ at temperatures between 293 and $333 \mathrm{~K}$. From the data, information on the kinetics of the reaction of MEA with bicarbonate $\left(\mathrm{HCO}_{3}{ }^{-}\right)$to form MEA carbamate was obtained. That reaction was investigated for the first time in the present work without using bicarbonate salts. An Arrhenius model was fitted to the new data. The formation of MEA carbamate from MEA and $\mathrm{HCO}_{3}{ }^{-}$is often neglected in models for describing the reactive absorption of $\mathrm{CO}_{2}$ with aqueous MEA solutions. A process simulation study carried out in the present work reveals that it should be taken into account in predictions of reactive absorption processes that are operated under elevated pressure with a high mole fraction of $\mathrm{CO}_{2}$ in the gaseous phase.

Keywords: reactive absorption, liquid phase reaction kinetics, carbon dioxide, monoethanolamine carbamate, in-situ NMR spectroscopy, rapid-mixing stopped-flow

\section{Introduction}

Reactive absorption is a common gas treatment process in the chemical industry. Examples include the removal of: phosgene with aqueous solutions of sodium hydroxide [1], nitrogen oxides with water or aqueous solutions of hydrogen peroxide, sulphuric oxides with water or with aqueous solutions of limestone [2], and ozone with aqueous solutions of hydrogen peroxide [3]. Another important example is the scrubbing of carbon dioxide $\left(\mathrm{CO}_{2}\right)$ and eventually hydrogen sulfide $\left(\mathrm{H}_{2} \mathrm{~S}\right)$ from natural gas, synthesis gases, and refinery gases [2]. The $\mathrm{CO}_{2}$ removal has also gained much attention in studies of Post-combustion Carbon Capture (PCC) [4, 5]. 
For the development and scale-up of reactive absorption processes, accurate physico-chemical models, especially for the description of reaction equilibria and kinetics in the liquid phase, are essential [6]. Reaction kinetic data in such systems are in most cases obtained from measurements, in which both mass transfer and reaction kinetics play a role. It is then very difficult to separate the two effects, which may lead to problems when the model is used for extrapolations. The present work aims at circumventing this problem. For one of the most important systems that are used in industry for the removal of $\mathrm{CO}_{2}$ by reactive absorption, reaction kinetic experiments were carried out, that are not influenced by mass transfer. A new way of carrying out such studies is described together with the results of its application.

Recently, Yang et al. [7] gave a review on the techniques for measuring reaction kinetics in aqueous amine solutions. Typically, the reaction rates are obtained from measurements of the absorption rate. Measurements of the absorption rate include laminar jet absorbers [8, 9, wetted wall columns [1012], string of discs columns [13] or stirred cell reactors [14, 15]. In order to deduce reaction rates from absorption rates, certain requirements on the experimental setup must be fulfilled, assumptions regarding the mass transfer from the gas into the liquid phase must be made, and reliable models of the phase equilibrium must be available [7]. Problems in fulfilling all these requirements have resulted in large scattering of the available experimental data [8].

For decreasing the error of the measurement of the reaction kinetics in the liquid phase, it is favorable to avoid any influence of the kinetics of the mass transfer of the $\mathrm{CO}_{2}$ into the liquid phase. One obvious way for obtaining 
information on liquid phase reaction kinetics in systems of the type amine$\mathrm{H}_{2} \mathrm{O}-\mathrm{CO}_{2}$ without any influence of gas-liquid mass transfer of $\mathrm{CO}_{2}$ is to mix two liquids of different composition and to monitor the composition as a function of time [7]. Experiments of this type have been carried out by several authors [16-23]. Most of these authors have used rapid-mixing experiments in the stopped-flow mode, in which $\mathrm{CO}_{2}$-loaded water was mixed with aqueous amine solutions. A drawback of this procedure is the low $\mathrm{CO}_{2}$ solubility in water which leads to initial concentrations of $\mathrm{CO}_{2}$ in these experiments which were always well below $1 \mathrm{~mol} \mathrm{l}^{-1}$. Also, methods have been used for monitoring the reactions in these experiments which only yield indirect information on the composition via measurements of $\mathrm{pH}$, electrical conductivity, or temperature. The lack of information on the individual species makes it difficult to develop a kinetic model for a system in which several reactions are taking place simultaneously. The time dependence of the concentration of individual species in such mixtures has only been studied by the group of Maeder [18, 19] who used NMR spectroscopy. However, their studies were carried out not with $\mathrm{CO}_{2}$ but with bicarbonate salts (e.g. $\mathrm{KHCO}_{3}$ ) and also using $\mathrm{HCl}$ and $\mathrm{NaOH}$, to keep the experimental setup and procedure simple. Hence, large amounts of alkali and halogenide ions were present in the solutions, which are typically not found in industrial $\mathrm{CO}_{2}$ absorption processes, but probably influence chemical equilibria and reaction rates $[24$.

In the present work, a new experimental method for studying reaction kinetics in systems of the type amine $-\mathrm{H}_{2} \mathrm{O}-\mathrm{CO}_{2}$ was developed. Equilibrated $\mathrm{CO}_{2}$-loaded and unloaded aqueous amine solutions are mixed. This mixing 
disturbs the chemical equilibrium and reactions lead to a new equilibrium state. The mixing is carried out in a rapid-mixing stopped-flow device in which the reactions are monitored by ${ }^{1} \mathrm{H}$ NMR spectroscopy. At its heart, the rapid-mixing stopped-flow device is an NMR probe with an integrated micromixer that was developed by our group and has been tested successfully on various chemical systems in previous studies [25-28].

That device is used here for studying the reaction kinetics in the system monoethanolamine (MEA) $-\mathrm{H}_{2} \mathrm{O}-\mathrm{CO}_{2}$. $\mathrm{MEA}$ is widely used in reactive $\mathrm{CO}_{2}$ absorption processes [29, 30]. As a consequence, plenty of data on the reaction kinetics in the system MEA- $\mathrm{H}_{2} \mathrm{O}-\mathrm{CO}_{2}$ are available in the literature, e.g. [8, 18, 19, 23, 31]. Most of the data were obtained with devices in which both mass transfer kinetics and chemical reaction kinetics play a role. Experiments were generally carried out to determine the rate of the reaction of MEA with $\mathrm{CO}_{2}$ to form MEA carbamate, which is very fast (half-lifes of reaction are of the order of 10 milliseconds). In film theory of mass transfer, this reaction must be taken into account in the film [32]. However, this reaction is so fast that it cannot be studied with the experimental method presented in this work. This method is limited to studies of kinetics of reactions with half-lifes of reaction of more than about five seconds. The focus in the present study is therefore the quantification of another kinetically controlled reaction that is known to take place in the liquid phase: the reaction of MEA with bicarbonate $\left(\mathrm{HCO}_{3}{ }^{-}\right)$to form MEA carbamate [18, 19]. The reverse reaction is the hydrolysis of MEA carbamate to MEA and $\mathrm{HCO}_{3}{ }^{-}$ and describes the stability of the MEA carbamate [19, 33, 34]. The reaction of MEA with $\mathrm{HCO}_{3}{ }^{-}$to MEA carbamate is usually not considered in 
the description of industrial $\mathrm{CO}_{2}$ absorption or PCC processes, as the concentration of $\mathrm{HCO}_{3}{ }^{-}$is low in most applications. Also, a kinetic model of our group, that was developed in previous works for describing PCC processes with MEA, did also not include this reaction [35]. However, Conway et al. [19] mentioned that industrial PCC processes exist in which the lean amine solution coming from the desorber contains substantial amounts of $\mathrm{HCO}_{3}{ }^{-}$. In that case, the reaction of $\mathrm{MEA}$ with $\mathrm{HCO}_{3}{ }^{-}$to $\mathrm{MEA}$ carbamate needs to be accounted for in the description of the absorber. The reaction of $\mathrm{MEA}$ with $\mathrm{HCO}_{3}{ }^{-}$to $\mathrm{MEA}$ carbamate has previously only been studied by the group of Maeder by mixing aqueous $\mathrm{KHCO}_{3}$ solutions with aqueous MEA solutions in NMR tubes and monitoring the reacting mixtures at room temperature by ${ }^{1} \mathrm{H}$ NMR spectroscopy [18, 19].

In the present work, the reaction of $\mathrm{MEA}$ with $\mathrm{HCO}_{3}{ }^{-}$to form $\mathrm{MEA}$ carbamate was measured at various temperatures (293, 303, 313, and $333 \mathrm{~K}$ ) and mass ratios of MEA / $\left(\mathrm{MEA}+\mathrm{H}_{2} \mathrm{O}\right)\left(0.15,0.255\right.$, and $\left.0.3 \mathrm{~g} \mathrm{~g}^{-1}\right)$. Based on the results, the kinetic model of our group described in [35] was extended with the reaction of $\mathrm{MEA}$ with $\mathrm{HCO}_{3}{ }^{-}$to MEA carbamate and rate constants of that reaction were determined. The reaction can now be described for a wide range of conditions that are relevant for industrial applications. The extended model was used in a process simulation study. This study revealed that the reaction of $\mathrm{MEA}$ with $\mathrm{HCO}_{3}{ }^{-}$is important to describe the absorption of $\mathrm{CO}_{2}$ in aqueous MEA solutions carried out under elevated pressure.

This paper is organized as follows: In Section 2 the chemical reactions in the system $\mathrm{MEA}-\mathrm{H}_{2} \mathrm{O}-\mathrm{CO}_{2}$ and the way in which they are described in the present work are briefly introduced. In Section 3 the experimental setup 
for the reaction kinetic studies and its operation are presented together with the evaluation of the ${ }^{1} \mathrm{H}$ NMR spectra. The modeling and the determination of the reaction rate constants is explained in Section 4. The results are discussed in Section 5. This chapter contains also the results from the process simulation study. Conclusions are drawn in Section 6 .

\section{Reaction System}

In the present work, the liquid phase reactions in the system $\mathrm{MEA}-\mathrm{H}_{2} \mathrm{O}-$ $\mathrm{CO}_{2}$ are described as follows. There are three instantaneous equilibrium reactions:

$$
\begin{gathered}
\mathrm{H}_{2} \mathrm{O} \leftrightharpoons \mathrm{H}^{+}+\mathrm{OH}^{-} \\
\mathrm{HCO}_{3}{ }^{-} \leftrightharpoons \mathrm{CO}_{3}{ }^{2-}+\mathrm{H}^{+} \\
\mathrm{MEAH}^{+} \leftrightharpoons \mathrm{MEA}+\mathrm{H}^{+}
\end{gathered}
$$

and two kinetically controlled equilibrium reactions:

$$
\begin{aligned}
& \mathrm{CO}_{2}+\mathrm{OH}^{-} \leftrightarrows \mathrm{HCO}_{3}^{-} \\
& \mathrm{MEA}+\mathrm{CO}_{2} \leftrightarrows \mathrm{MEACOO}^{-}+\mathrm{H}^{+}
\end{aligned}
$$

This reaction system was used for example by von Harbou et al. [35], who developed a model of the physico-chemical properties relevant for reactive absorption of $\mathrm{CO}_{2}$ in aqueous MEA solutions. The model of von Harbou et al. [35] is a modification and extension of the model of Wagner et al. [36], which describes the vapor-liquid equilibrium of the system $\mathrm{MEA}-\mathrm{H}_{2} \mathrm{O}-\mathrm{CO}_{2}$. 
At high concentrations of $\mathrm{HCO}_{3}^{-}$(i.e. high $\mathrm{CO}_{2}$ loading), the kinetically controlled equilibrium reaction of MEA with $\mathrm{HCO}_{3}{ }^{-}$plays a role [18, 19]:

$$
\mathrm{MEA}+\mathrm{HCO}_{3}^{-} \leftrightarrows \mathrm{MEACOO}^{-}+\mathrm{H}_{2} \mathrm{O}
$$

This reaction was added in the present work to the model of von Harbou et al. [35] and the forward reaction rate constant was fitted to the experimental data as described in Section 4 .

The equilibrium constant of Reaction (VI) can be calculated from the equilibrium constants of Reactions (I), (IV), and (V). Hence, for describing equilibria, adding Reaction (VI) to the reaction system (I)-(V) makes no difference. Adding Reaction (VI) does, however, influence the reaction kinetics of the reaction system, which is shown in Section 5.

Many more reactions can take place, which, however, either are degradation reactions [37] which are not considered in the present work or are not relevant for industrial applications [38].

\section{Experimental}

\subsection{Chemicals}

Monoethanolamine (MEA, $\geqslant 99.0$ mass \%) was purchased from SigmaAldrich. Carbon Dioxide $\left(\mathrm{CO}_{2}, \geqslant 99.995\right.$ vol \%) was purchased from Air Liquide. Water was deionized and purified with a water purification system (Milli-Q Reference $\mathrm{A}+$ system, Merck Millipore). Methanol (Hydranal ${ }^{\mathrm{TM}}$ Methanol dry, water content $\leqslant 0.01$ mass \%) was purchased from Honeywell. Ethanol (Uvasol ${ }^{\circledR}$ Ethanol for spectroscopy, $\geqslant 99.9$ mass \%) was purchased from Merck. 


\subsection{Experimental Setup and Procedure}

The setup is shown in Figure 1. Two syringe pumps A and B (Dual 260D, Teledyne Isco) equipped with the pressure sensors PIR1 and PI2 were connected via two feed lines with a micromixer probe mounted in an NMR spectrometer (Magnet: Ascend 400, Console: Avance 3 HD 400, Bruker). The micromixer probe was developed by our group in a cooperation with Fraunhofer IMM and Bruker and was first described by Brächer et al. [25]. It has been applied successfully in reaction kinetic studies of various systems [26-28]. The probe incorporates a micromixer, in which the reactants (solutions A and B) are mixed, and an NMR flow cell equipped with the measuring coil. Each feed line was equipped with a Coriolis mass flow meter (FIR1 \& FIR2, mini Cori-Flow M12, Bronkhorst, uncertainties stated by the supplier: relative standard uncertainty of mass flow rate: $u_{\mathrm{r}}(\dot{m})=0.002$, standard uncertainty of density: $u(\rho)=5 \mathrm{~kg} \mathrm{~m}^{-3}$ ) and $0.5 \mu \mathrm{m}$ filters to prevent clogging of the micromixer. The outlet line of the micromixer probe was connected with a pressurized steel container. A pressure sensor (PIR3, P-31, WIKA) was placed in the outlet line. The two feed lines and the outlet line could be shut simultaneously by two 2-position, 6 -port motorized valves (V2 \& V3, Rheodyne MXP7900, IDEX Health \& Science). The motorized valves received their closing signal from the NMR console so that the time between the closing of the valves and the recording of the first NMR spectrum could be set with high accuracy (estimated accuracy between closing and first recorded NMR spectra: $u(t)=0.1 \mathrm{~s}$ ). All lines were capillaries of $1 / 16 "$ outer diameter and 0.25 or $0.75 \mathrm{~mm}$ inner diameter made of poly ether ether ketone (PEEK). 
The setup was used to mix a $\mathrm{CO}_{2}$-loaded aqueous MEA solution with an unloaded aqueous MEA solution in stopped-flow rapid-mixing experiments. The mixing disturbs the chemical equilibrium and creates a driving force of reaction to a new equilibrium state. In Figure 2, the composition of $\mathrm{CO}_{2}{ }^{-}$ loaded aqueous MEA solutions with a mass fraction of MEA of $x_{\mathrm{MEA}}^{(\mathrm{m}), 0}=$ $0.3 \mathrm{~g} \mathrm{~g}^{-1}$ in the unloaded solutions is shown for a temperature of $298 \mathrm{~K}$. The results were obtained using the model of Wagner et al. [36]. The $\mathrm{CO}_{2}$ loading, $\alpha_{\mathrm{CO}_{2}}$, is defined as the overall amount of $\mathrm{CO}_{2}, \widetilde{n}_{\mathrm{CO}_{2}}$, related to the overall amount of MEA, $\widetilde{n}_{\mathrm{MEA}}$ :

$$
\alpha_{\mathrm{CO}_{2}}=\frac{\widetilde{n}_{\mathrm{CO}_{2}}}{\widetilde{n}_{\mathrm{MEA}}}
$$

In Figure 2, also results for an isothermal experiment are illustrated, in which a $\mathrm{CO}_{2}$-loaded solution with $\alpha_{\mathrm{CO}_{2}}=0.8 \mathrm{~mol} \mathrm{~mol}^{-1}$ is mixed with unloaded solution. In both solutions, $x_{\mathrm{MEA}}^{(\mathrm{m}), 0}$ is the same. In Figure 2, "A" marks the $\mathrm{CO}_{2}$-loaded solution, "B" marks the unloaded solution, and "mix" marks the resulting reacting mixture. The mixing and the driving force of reaction for species $\mathrm{MEAH}_{\mathrm{x}}$ (which stands for MEA and its protonated form) as well as the carbamate $\mathrm{MEACOO}^{-}$are indicated with straight lines and arrows.

Three measurement series (named a,b, and c) with different mass fraction of MEA, $x_{\mathrm{MEA}}^{(\mathrm{m}), 0}$, in the unloaded stock solution and $\mathrm{CO}_{2}$ loading, $\alpha_{\mathrm{CO}_{2}}^{\mathrm{A}}$, in the $\mathrm{CO}_{2}$-loaded solution A were conducted. An overview of the measurement series is given in Table 1.

Only $\mathrm{MEAH}_{\mathrm{x}}$ and $\mathrm{MEACOO}^{-}$were measured with NMR spectroscopy. As a consequence, the $\mathrm{CO}_{2}$ loading, $\alpha_{\mathrm{CO}_{2}}^{\text {mix }}$, in the reacting mixture was not 
Table 1: Overview of the measurement series conducted in the present work at different mass fractions of MEA $x_{\mathrm{MEA}}^{(\mathrm{m}), 0}$ in the unloaded stock solution, $\mathrm{CO}_{2}$ loadings $\alpha_{\mathrm{CO}_{2}}^{\mathrm{A}}$ in the $\mathrm{CO}_{2}$-loaded solution $\mathrm{A}, \mathrm{CO}_{2}$ loadings $\alpha_{\mathrm{CO}_{2}}^{\text {mix }}$ in the reacting mixture, and temperature $T$.

\begin{tabular}{lllll}
\hline & $\begin{array}{l}x_{\mathrm{MEA}}^{(\mathrm{m}), 0} \\
\mathrm{~g} \mathrm{~g}^{-1}\end{array}$ & $\begin{array}{l}\alpha_{\mathrm{CO}_{2}}^{\mathrm{A}} \\
\mathrm{mol} \mathrm{mol}^{-1}\end{array}$ & $\begin{array}{l}\alpha_{\mathrm{CO}}^{\mathrm{mix}} \\
\mathrm{mol} \mathrm{mol}^{-1}\end{array}$ & $\mathrm{~K}$ \\
\hline $\mathrm{a}$ & 0.300 & 0.798 & 0.39 & $303,313,333$ \\
$\mathrm{~b}$ & 0.225 & 0.873 & 0.43 & $293,303,313,333$ \\
$\mathrm{c}$ & 0.150 & 0.995 & 0.49 & $293,303,313,333$ \\
\hline
\end{tabular}

available from the NMR spectra. For the same reason, the initial concentration of each species right after mixing, which is paramount for the evaluation of a kinetic experiment, was not available from the first NMR spectrum. Hence, $\alpha_{\mathrm{CO}_{2}}^{\operatorname{mix}}$ and the initial concentration of each species were calculated from the mass flows in the two feed lines before stopping the pumps as well as from $x_{\mathrm{MEA}}^{(\mathrm{m}), 0}$ and $\alpha_{\mathrm{CO}_{2}}^{\mathrm{A}}$. The mass flows were measured by the Coriolis mass flow meters. $x_{\mathrm{MEA}}^{(\mathrm{m}), 0}$ and $\alpha_{\mathrm{CO}_{2}}^{\mathrm{A}}$ were known from the sample preparation. The calculation of $\alpha_{\mathrm{CO}_{2}}^{\mathrm{mix}}$ and of the concentration of each species right after mixing is presented in the Supplementary Material. In addition, a sensitivity analysis of experimental errors of $\alpha_{\mathrm{CO}_{2}}^{\mathrm{A}}$ and of the mass flows on the evaluation of a kinetic experiment is presented there.

For each measurement series, about $500 \mathrm{~g}$ of aqueous MEA solution were prepared under vacuum in a glass cylinder. The composition, $x_{\mathrm{MEA}}^{(\mathrm{m}), 0}$, was determined gravimetrically using a laboratory balance (PR2003 Comparator, Mettler Toledo, estimated standard uncertainty of the mass fraction of MEA: $\left.u\left(x_{\mathrm{MEA}}^{(\mathrm{m}), 0}\right)=0.00002 \mathrm{~g} \mathrm{~g}^{-1}\right)$. About half of the solution was loaded with $\mathrm{CO}_{2}$ in a pressure resistant stainless steel container. The $\mathrm{CO}_{2}$ loading, $\alpha_{\mathrm{CO}_{2}}^{\mathrm{A}}$, was determined gravimetrically using the same laboratory balance (estimated 
standard uncertainty of the $\mathrm{CO}_{2}$ loading: $\left.u\left(\alpha_{\mathrm{CO}_{2}}^{\mathrm{A}}\right)=0.001 \mathrm{~mol} \mathrm{~mol}{ }^{-1}\right)$. Details on the procedure are given in a previous work of our group [38.

The $\mathrm{CO}_{2}$-loaded and the unloaded solution were filled separately into the syringe pumps A and B. Prior to the filling of the pumps with a new solution, they were carefully flushed and dried. After filling, the whole setup was pressurized to prevent degassing of $\mathrm{CO}_{2}$ during the measurement. For this purpose, the steel container located at the end of the setup was pressurized with $\mathrm{N}_{2}$. A pressure of $\mathrm{N}_{2}$ was chosen that was at least 5 bar larger than the equilibrium pressure of the $\mathrm{CO}_{2}$-loaded aqueous MEA solution at the given conditions.

The syringe pumps were thermostatted with water (F32/HE thermostat, Julabo). When changing the temperature, the syringe pumps were thermostatted for at least 30 minutes at $333 \mathrm{~K}$, for 1 hour at $313 \mathrm{~K}$ or for 4 hours at 293 and $303 \mathrm{~K}$. This procedure ensured that equilibrium conditions were reached inside both syringe pumps prior to a kinetic experiment. The flow cell, the micromixer and all capillaries inside the micromixer probe were thermostatted with the thermo fluid FC-43 (perfluorotributylamine). The temperature of the thermo fluid was controlled by a thermostat (Petite fleur Two to Tango, Peter Huber Kältemaschinenbau AG), which used the reading of a copper/copper-nickel thermo couple (Type T, Temperatur Messelemente Hettstedt) installed beneath the micromixer as actual value for calculating the difference from the set-point. The temperature control was calibrated in experiments with methanol as described by Ammann et al. [39]. The probe facilitates isothermal reaction conditions during measurements as demonstrated in a previous work [28]. The estimated accuracy of the ther- 
mostatization is $\pm 1 \mathrm{~K}[27$.

At the beginning of each kinetic experiment, an equal volume flow was set for both syringe pumps. The total volume flow was set large enough to guarantee sufficient mixing. Sufficient mixing was indicated by undistorted peaks [28]. An automated measurement sequence operated by the NMR spectrometer was started when the flow in both feed lines reached a steady state. In this sequence, one spectrum was measured while the reactant solutions were still flowing. Then, the motorized valves switched to the stop position and repetitive ${ }^{1} \mathrm{H}$ NMR measurements were performed.

The recorded data of all experiments, an assessment of the temperature profile during a kinetic experiment, and the automated NMR measurement sequence are given in the Supplementary Material.

\subsection{NMR Spectroscopy and Data Analysis}

The composition of the liquid phase was determined by quantitative ${ }^{1} \mathrm{H}$ NMR spectroscopy. Prior to every measurement series and after every change of temperature, tuning of the resonance circuit, matching of the impedance and shimming of the magnet was carried out manually using the $\mathrm{CO}_{2}$-loaded aqueous MEA solution. No lock system was used due to the high stability of the magnet. All quantitative measurements were carried out with a $30^{\circ}$ flip angle, $5-180 \mathrm{~s}$ pulse repetition, and single scans. For a $30^{\circ}$ flip angle, the pulse repetition time should be at least about $2.6 \times T_{1}$ to ensure quantitative measurements [40]. The longest $T_{1}$ was measured for the $\mathrm{CH}_{2}$ groups of MEA $\left(T_{1}=1.8 \mathrm{~s}\right)$ thus this requirement was always fulfilled. The postprocessing was carried out manually. The peak areas were determined by direct integration. The full set of NMR acquisition parameters is listed in 
the Supplementary Material.

Figure 3 shows the stacked spectra of Experiment a2 (for experimental conditions see Table 2). For reasons of clarity, only the peaks of $\mathrm{MEA} / \mathrm{MEAH}^{+}$ and $\mathrm{MEACOO}^{-}$, and only 50 out of the more than 400 spectra are depicted in Figure 3. The peak assignment shown in Figure 3 is the result of two-dimensional NMR measurements conducted in a previous work of our group [38]. The protonated and the unprotonated form of MEA cannot be distinguished by NMR spectroscopy. In the spectra and for the evaluation, the two species are summarized as $\mathrm{MEAH}_{\mathrm{x}}$. No reference and no lock component was added to the solutions. Therefore, the chemical shifts reported in Figure 3 do not match reported values in the literature.

Outside the region shown in Figure 3, there is one additional peak of $\mathrm{MEACOO}^{-}$which results from the stabilized proton attached to the nitrogen atom of the carbamate group. Because of its low intensity and its partial overlapping with the water peak, this peak was not evaluated. Furthermore, the peak that is the sum of the signals of water, $\mathrm{OH}$ groups, fast exchanging protons of the $\mathrm{NH}_{2}$ and $\mathrm{NH}_{3}{ }^{+}$group of $\mathrm{MEAH}_{\mathrm{x}}$ and fast exchanging protons of the carbonates was not considered.

Small quantities of the monoalkylcarbonates of MEA were also detected as reactants in the ${ }^{1} \mathrm{H}$ NMR spectra. The formation of monoalkylcarbonates in the system $\mathrm{MEA}-\mathrm{H}_{2} \mathrm{O}-\mathrm{CO}_{2}$ was recently studied in detail by our group [38. They are observed only for high $\mathrm{CO}_{2}$ loadings. In the present experiments, they are therefore only present in the $\mathrm{CO}_{2}$-loaded solution that is mixed with the unloaded solution. The concentration of the monoalkylcarbonates in the mixed solutions in equilibrium is below the detection limit. 
After the mixing, the corresponding signals, which are small even at the beginning, vanish quickly (after about $75 \mathrm{~s}$ at $293 \mathrm{~K}, 20 \mathrm{~s}$ at $303 \mathrm{~K}$, and $10 \mathrm{~s}$ at $313 \mathrm{~K}$ ). At $333 \mathrm{~K}$ no monoalkylcarbonates were detected at all. Thus, the monoalkylcarbonates are not further considered in the present work.

Because of the overlapping, superposition and small intensity of all peaks outside the region that is depicted in Figure 3 , only the peaks of the $\mathrm{CH}_{2}$ groups of $\mathrm{MEAH}_{\mathrm{x}}$ (peak 20 and 30; see Figure 3) and MEACOO- (peak 21 and 31; see Figure 31 were evaluated. The results of the NMR measurements are expressed as molar ratios, $\zeta_{i}$, of the amount, $n_{i}$, of species $i$ related to the sum of the amount of $\mathrm{MEAH}_{\mathrm{x}}$ and $\mathrm{MEACOO}^{-}$.

$$
\zeta_{i}=\frac{n_{i}}{n_{\mathrm{MEAH}_{\mathrm{x}}}+n_{\mathrm{MEACOO}^{-}}} \text {for: } i=\left\{\mathrm{MEAH}_{\mathrm{x}}, \mathrm{MEACOO}^{-}\right\}
$$

Because of the chosen NMR sequence, the peak areas of the $\mathrm{CH}_{2}$ groups of $\mathrm{MEAH}_{\mathrm{x}}$ and $\mathrm{MEACOO}^{-}$were directly proportional to the number of nuclei that caused the peak. Hence, the observed values of $\zeta_{i}^{\text {obs }}$ are calculated from:

$$
\zeta_{i}^{\mathrm{obs}}=\frac{A_{i}}{A_{\mathrm{MEAH}_{\mathrm{x}}}+A_{\mathrm{MEACOO}^{-}}} \text {for: } i=\left\{\mathrm{MEAH}_{\mathrm{x}}, \mathrm{MEACOO}^{-}\right\}
$$

where $A_{\mathrm{MEAH}_{\mathrm{x}}}$ and $A_{\mathrm{MEACOO}^{-}}$are the mean of the peak areas of the corresponding $\mathrm{CH}_{2}$ groups of $\mathrm{MEAH}_{\mathrm{x}}$ and $\mathrm{MEACOO}^{-}$. As the relative position of peaks in an NMR spectrum is a function of composition and temperature, the peaks of two $\mathrm{CH}_{2}$ groups overlapped in some kinetic experiments. For those experiments, only one peak of each species (i.e. either peaks 20 and 21 or peaks 30 and 31; see Figure 3) was evaluated. All results for the peak 
areas are provided in the Supplementary Material, in which the peaks areas that were evaluated are highlighted.

The accuracy of $\zeta_{i}^{\text {obs }}$ was evaluated via a test measurement with a nonreactive system. An aqueous solution containing $0.3 \mathrm{~g} \mathrm{~g}^{-1} \mathrm{MEA}$ was mixed with an aqueous solution containing $0.226 \mathrm{~g} \mathrm{~g}^{-1}$ ethanol. The mixing was conducted in a stopped-flow experiment with the same parameters that were also used for the kinetic experiments. Ten ${ }^{1} \mathrm{H}$ NMR spectra were taken after the flow was stopped. The $95 \%$ confidence intervall of $\zeta_{i}^{\text {obs }}$ was found to be $\pm 0.002 \mathrm{~mol} \mathrm{~mol}^{-1}$. Comparing the average of $\zeta_{i}^{\text {obs }}$, which were obtained from the ${ }^{1} \mathrm{H}$ NMR spectra, with the expected value, which was calculated from the gravimetric sample preparation and the mass flow measurements, yielded a relative deviation of $4 \%$. As expected, this deviation is larger than in an undiluted test measurement, because of smaller NMR peaks [27. Hence, in the present work, the relative standard uncertainty of the NMR measurements was estimated to be $u_{\mathrm{r}}\left(\zeta_{i}^{\mathrm{obs}}\right)=0.04$.

The NMR results expressed as molar ratios, $\zeta_{\mathrm{MEAH}_{\mathrm{x}}}^{\mathrm{obs}}$ and $\zeta_{\mathrm{MEACOO}^{-}}^{\mathrm{obs}}$, were directly used for the parameter estimation procedure without any further conversion (see next section). In the presentation of the experimental data, we use the mole fraction, $x_{i}^{\mathrm{obs}}$, where $i$ refers to $\mathrm{MEAH}_{\mathrm{x}}, \mathrm{MEACOO}^{-}, \mathrm{H}_{\mathrm{x}} \mathrm{CO}_{3}$, 
and $\mathrm{H}_{2} \mathrm{O}$, see Equations (4)-(6).

$$
\begin{aligned}
x_{i}^{\mathrm{obs}} & =\frac{\zeta_{i}^{\mathrm{obs}}}{X_{\mathrm{H}_{2} \mathrm{O}, \mathrm{MEA}}^{(\mathrm{n}, 0 \mathrm{obs}}+1} \text { for: } i=\left\{\mathrm{MEAH}_{\mathrm{x}}, \mathrm{MEACOO}^{-}\right\} \\
x_{\mathrm{H}_{\mathrm{x}} \mathrm{CO}_{3}}^{\mathrm{obs}} & =\frac{\alpha_{\mathrm{CO}_{2}}^{\mathrm{mix}}-\zeta_{\mathrm{MEACOO}^{-}}^{\mathrm{obs}}}{X_{\mathrm{H}_{2} \mathrm{O}, \mathrm{MEA}}^{(\mathrm{n}), 0, \mathrm{Mbs}}+1} \\
x_{\mathrm{H}_{2} \mathrm{O}}^{\mathrm{obs}} & =\frac{X_{\mathrm{H}_{2} \mathrm{O}, \mathrm{MEA}}^{(\mathrm{n}), 0 \mathrm{obs}}-\alpha_{\mathrm{CO}_{2}}^{\mathrm{mix}}+\zeta_{\mathrm{MEACOO}^{-}}^{\mathrm{obs}}}{X_{\mathrm{H}_{2} \mathrm{O}, \mathrm{MEA}}^{(\mathrm{n}), 0, \mathrm{Ms}}+1}
\end{aligned}
$$

where $X_{\mathrm{H}_{2} \mathrm{O}, \text { MEA }}^{(\mathrm{n}) 0 \text {,obs }}$ is the molar loading of MEA with water in the unloaded stock solution, which is available from the gravimetric preparation of the samples. $x_{\mathrm{H}_{\mathrm{x}} \mathrm{CO}_{3}}^{\mathrm{obs}}$ is the combined mole fraction of $\mathrm{CO}_{3}{ }^{2-}$ and $\mathrm{HCO}_{3}{ }^{-}$. For the calculation of $x_{i}^{\text {obs }}$, the amount of molecular $\mathrm{CO}_{2}, \mathrm{OH}^{-}$, and $\mathrm{H}^{+}$was neglected. The model results of the kinetic experiments, which are presented in Section 5, justify this simplification.

\section{Modeling and Parameter Estimation}

The mole fraction, $x_{i}$, of species $i$ out of a total of $N$ species changes in a reacting solution according to Equation (7).

$$
x_{i}=\frac{x_{i}\left(t_{0}\right)+\sum_{j=1}^{R} \nu_{i, j} \lambda_{j}}{1+\sum_{j=1}^{R} \sum_{i=1}^{N} \nu_{i, j} \lambda_{j}}
$$

where $x_{i}\left(t_{0}\right)$ is the mole fraction of species $i$ at the beginning of the reaction, $\nu_{i, j}$ is the stoichiometric coefficient of species $i$ in reaction $j$, and $\lambda_{j}$ is the extent of reaction for reaction $j$ out of $R$ reactions. $\lambda_{j}$ is related 
to the total amount of all species, $n_{\text {tot }}\left(t_{0}\right)$, at the beginning of the reaction. The initial values $x_{i}\left(t_{0}\right)$ at the start of the reaction were determined from the mixing of the solutions A and B (c.f. Figure 2), which were in chemical equilibrium before mixing. The compositions in the chemical equilibrium of the solutions A and B were calculated with the equilibrium model of Wagner et al. [36]. Details on the calculation of $x_{i}\left(t_{0}\right)$ are given in the Supplementary Material.

The chemical equilibrium of the instantaneous chemical reaction $j$ (with $j=\mathrm{I}$. II III is described here as suggested by Wagner et al. [36] using chemical equilibrium constants, $K_{\mathrm{a}, j}$, and molality-based activities, $a_{i}$, normalized similar to Henry's law for all solutes (including MEA) and a mole fraction based activity normalized according to Raoult's law for water:

$$
\begin{aligned}
K_{\mathrm{a}, j}(T) & =\prod_{i}^{N} a_{i}^{\nu_{i, j}} \\
\text { with } a_{\mathrm{H}_{2} \mathrm{O}} & =x_{\mathrm{H}_{2} \mathrm{O}} \cdot \gamma_{\mathrm{H}_{2} \mathrm{O}} \\
\text { and } a_{i} & =\frac{m_{i}}{m^{0}} \gamma_{i}^{\mathrm{m} *} \text { for all } i \neq \mathrm{H}_{2} \mathrm{O} .
\end{aligned}
$$

where $\gamma_{\mathrm{H}_{2} \mathrm{O}}$ is the mole fraction based activity coefficient of water, $m_{i}$ is the molality of species $i, m^{0}$ is a hypothetical one molal solution of solute $i$ in pure water as reference state, and $\gamma_{i}^{\mathrm{m} *}$ is the molality-based activity coefficient of species $i$ (except for water). The dependence of the chemical potential on pressure was neglected, so that $K_{\mathrm{a}, j}$ is only a function of temperature. The temperature dependence of $K_{\mathrm{a}, j}$ is described by empirical correlations. These correlations were taken from Wagner et al. [36]. $\gamma_{i}^{\mathrm{m} *}$ is calculated using an extended form of Pitzer's equation [41, 42]. Where avail- 
able, the interaction parameters were taken from Wagner et al. [36]. $\gamma_{\mathrm{H}_{2} \mathrm{O}}$ is calculated from the Gibbs-Duhem equation.

The reaction rate, $r_{j}$, of the kinetically controlled equilibrium reaction $j$ (with $j=\mathrm{IV}, \mathrm{V}, \mathrm{VI}$ ), as defined in the present work, is related to the volume, $V$. The change of the composition in the NMR flow cell with time was described with a simple batch reactor model, see Equation (9).

$$
\frac{\mathrm{d} \lambda_{j}}{\mathrm{~d} t}=r_{j}(T) v^{\mathrm{mix}}
$$

where $v^{\text {mix }}$ is the molar volume of the reacting mixture, defined here as $v^{\text {mix }}=V / n_{\text {tot }}\left(t_{0}\right)$. The calculation of the molar volume is presented in the Supplementary Material.

For the kinetically controlled equilibrium reactions $(\mathrm{IV}), \mathrm{V})$, and $(\mathrm{VI}), r_{j}$ is defined as

$$
\begin{aligned}
& r_{j}(T)=k_{\mathrm{f}, j}(T)\left(\prod_{i=1}^{N_{\text {reactants }, j}} a_{i}^{\left|\nu_{i, j}\right|}-\frac{1}{K_{\mathrm{a}, j}(T)} \prod_{i=1}^{N_{\text {products }, j}} a_{i}^{\nu_{i, j}}\right) \\
& \text { with } k_{\mathrm{f}, j}(T)=k_{\mathrm{f}, j}^{0} \exp \left(-\frac{E_{\mathrm{A}, j}}{R T}\right) \text { for: } j=\{\mathrm{IV}, \mathrm{V}\}
\end{aligned}
$$

where $k_{\mathrm{f}, j}$ is the forward reaction rate constant, $k_{\mathrm{f}, j}^{0}$ is the pre-exponential factor, $E_{\mathrm{A}, j}$ is the activation energy, and $R$ is the universal gas constant. The temperature dependence of $k_{\mathrm{f}, j}$ is described by Arrhenius' law. The Arrhenius parameters $k_{\mathrm{f}, j}^{0}$ and $E_{\mathrm{A}, j}$ were taken from von Harbou et al. [35]. The temperature-dependent correlations of the equilibrium constants were calculated from the information on the equilibrium constants of reactions that are reported in the model of Wagner et al. [36] (c.f. [35] and Supplementary 
Material).

For Reaction $(\overline{\mathrm{VI}})$ a dependence of the pre-exponential factor on the mass fraction, $x_{\mathrm{MEA}}^{(\mathrm{m}), 0}$, of MEA in the unloaded stock solution was observed. In order to obtain one pre-exponential factor, $k_{\mathrm{f}, \mathrm{VI}}^{0, *}$, that is independent from $x_{\mathrm{MEA}}^{(\mathrm{m}), 0}$, an adjusted form of the forward reaction rate constant is defined.

$$
\begin{aligned}
& k_{\mathrm{f}, \mathrm{VI}}(T)=\frac{1}{x_{\mathrm{MEA}, 0}^{(\mathrm{m}),}} k_{\mathrm{f}, \mathrm{VI}}^{*}(T) \\
& \text { with } k_{\mathrm{f}, \mathrm{VI}}^{*}(T)=k_{\mathrm{f}, \mathrm{VI}}^{0, *} \exp \left(-\frac{E_{\mathrm{A}, \mathrm{VI}}}{R T}\right)
\end{aligned}
$$

The temperature-dependent correlation for $K_{\mathrm{a}, \mathrm{VI}}$ was taken from Wagner et al. [36]. All interaction parameters, empirical correlations for the chemical equilibrium constants, and forward reaction rate constants are listed in the Supplementary Material.

We have also tested some alternative reaction kinetic models. The one that is presented here is the simplest that we have found that gives a good description of our reaction kinetic data after the adjustment of the parameters. No model was found that accomplishes this without the concentrationdependent pre-exponential factor in Equation (11). In order to describe the chemical equilibrium in the same way as in the model of Wagner et al. [36], no additional components (e.g. $\mathrm{H}_{2} \mathrm{CO}_{3}$ ) were included in the model.

The Equations (8) and (9) make up a differential-algebraic equation system (DAE) that was solved with the ode15s solver of MATLAB 2017b (The Mathworks). The resulting mole fractions, $x_{i}^{\text {model }}$, are converted to molar 
ratios, $\zeta_{i}^{\text {model }}$, see Equation 12 .

$$
\zeta_{i}^{\text {model }}=\frac{x_{i}}{x_{\mathrm{MEAH}_{\mathrm{x}}}+x_{\mathrm{MEACOO}^{-}}} \text {for: } i=\left\{\mathrm{MEAH}_{\mathrm{x}}, \mathrm{MEACOO}^{-}\right\}
$$

with $x_{\mathrm{MEAH}_{\mathrm{x}}}=x_{\mathrm{MEA}}+x_{\mathrm{MEAH}^{+}}$

$k_{\mathrm{f}, \mathrm{VI}}^{*}$ was determined by solving the minimization problem using the sum of squared errors as objective function:

$$
\begin{aligned}
k_{\mathrm{f}, \mathrm{VI}}^{*}\left(T_{l}\right) & =\underset{k_{\mathrm{f}, \mathrm{VI}}^{*} \in \mathbb{R}^{+}}{\arg \min } \sum_{k=1}^{M_{l}} \sum_{i=1}^{2}\left(\zeta_{i, k}^{\mathrm{obs}}-\zeta_{i}^{\text {model }}\left(t_{k}, k_{\mathrm{f}, \mathrm{VI}}^{*}\left(T_{l}\right), \alpha_{\mathrm{CO}_{2}, k}^{\mathrm{mix}, \mathrm{obs}}, x_{\mathrm{MEA}, k}^{(\mathrm{m}), 0, \mathrm{obs}}\right)\right)^{2} \\
i & =\left\{1 \text { for } \mathrm{MEAH}_{\mathrm{x}}, 2 \text { for } \mathrm{MEACOO}^{-}\right\} \\
k & =1 \ldots M_{l}
\end{aligned}
$$

where $M_{l}$ is the total number of NMR spectra taken in one kinetic experiment and $t_{k}$ is the time between the start of the kinetic experiment (i.e. the closing of the valves) and the start of the measurement of the $k$-th NMR spectrum (i.e. the emission of the radio-frequency pulse). The acquisition time of the spectrum (about $1 \mathrm{~s}$ ) was short compared to $t_{k}$. The optimization problem was solved with MATLAB's nlinfit function.

\section{Results and Discussion}

Figure 4 shows a typical example of a concentration profile that was

obtained in the kinetic experiments. The results that are depicted in Figure 4 were obtained in the Experiment a2, of which the spectra were already shown in Figure 3. In Figure 4, the experimental data is plotted together with their 
prediction by the model of von Harbou et al. [35]. As expected, the model of von Harbou et al. [35], which does not take into account the reaction of MEA with $\mathrm{HCO}_{3}{ }^{-}$(Reaction (VI) , does not predict the observed composition profile well: The reaction rate is heavily underestimated. An underestimation of the reaction rate was also observed by Conway et al. [19], when they compared the data of their mixing experiment of aqueous MEA solutions with aqueous bicarbonate salt solutions with a model that did not include the reaction of MEA with $\mathrm{HCO}_{3}{ }^{-}$. Introducing Reaction (VI) into the model of von Harbou et al. [35] and fitting the forward reaction rate yielded a very good description of the experimental data (c.f. Figure 4). The good agreement between experimental and modeled equilibrium composition at the end of the experiment $(t \rightarrow \infty)$ is not the result of the parameter estimation. The equilibrium composition is a prediction of the equilibrium model of Wagner et al. [36], which is the basis of the kinetic model of von Harbou et al. [35] and thus the basis of the kinetic model developed in this work. As the equilibrium model of Wagner et al. [36] is known to yield good predictions of the equilibrium composition for $\mathrm{CO}_{2}$ loadings up to $0.5 \mathrm{~mol} \mathrm{~mol}^{-1}$ (i.e. the loading range of the mixed solutions, c.f. [38]), the good agreement with the experimental results from the present work indicates that the analytical procedure of the present work is correct as well as the determination of the mass flow ratio of the two feed solutions $\mathrm{A}$ and $\mathrm{B}$.

Figure 5 shows the composition over time for different experiments. Here, the experimental data is compared only with the model results from the present work that includes Reaction (VI). Along with mole fractions of species that were measured, also the calculated mole fractions of MEA and $\mathrm{MEAH}^{+}$ 
as well as $\mathrm{CO}_{3}{ }^{2-}$ and $\mathrm{HCO}_{3}{ }^{-}$are plotted. The model results of $x_{\mathrm{CO}_{2}}, x_{\mathrm{H}^{+}}$, and $x_{\mathrm{OH}^{-}}$are always below $0.001 \mathrm{~mol} \mathrm{~mol}{ }^{-1}$ and are therefore not shown. For clarity, the mole fraction of $\mathrm{H}_{2} \mathrm{O}$ is not shown either. In all cases, the model results agree well with the experimental data. This good agreement also holds for all other experiments, which are not shown here. Comparing the cases of the same measurement series with each other (i.e. same mass fraction of MEA, $x_{\mathrm{MEA}, 0}^{(\mathrm{m})}$, in the unloaded stock solution) reveals the strong influence of temperature on the reaction rate: Increasing the temperature by $30 \mathrm{~K}$ increases the reaction rate by a factor of about 60 (note that different time units are used in the plots in Figure 57. Comparing the cases of the same temperature with each other (i.e. different $x_{\mathrm{MEA}}^{(\mathrm{m}), 0}$ ) reveals the slight influence of $x_{\mathrm{MEA}}^{(\mathrm{m}), 0}$ on the reaction rate: Smaller $x_{\mathrm{MEA}}^{(\mathrm{m}), 0}$ increases the reaction rate. This influence is considered in the adjusted form of the forward reaction rate constant, $k_{\mathrm{f}, \mathrm{VI}}^{*}$, of Reaction (VI) (c.f. Equation (11)).

Figure 6 depicts the model results of the extent of all reactions divided by the molar volume of the mixture as a function of time for Experiment a2. Figure 6 also shows the behavior of the system right after mixing. Because of the sudden change of $\mathrm{pH}$, the extent of Reaction (III) and (III) changes instantaneously according to the model assumption at $t=0 \mathrm{~s}$. Moreover, a small change in the extent of Reaction $(\mathrm{V})$ is apparent, which is due to the residue of molecular $\mathrm{CO}_{2}$ in solution $\mathrm{A}$. This residue completely reacts to $\mathrm{MEACOO}^{-}$according to Reaction $(\mathrm{V})$ in less than a second. In the following, all reactions take place but at a much slower rate. Two groups of reactions can be identified, where the absolute changes of the extents of reaction and the absolute rates of reaction respectively are the same: The first group 
consists of Reaction (II), (III), and (VI) and the second group comprises Reaction (I), (IV), and (V). For both groups of reactions, one reaction is the rate-determining reaction. The rate-determining reaction of the first group is the kinetically controlled Reaction (VI). For every $\mathrm{MEA}$ and $\mathrm{HCO}_{3}{ }^{-}$that is consumed according to Reaction (VI), new MEA is instantaneously formed by deprotonation of free $\mathrm{MEAH}^{+}$according to Reaction (III) and new $\mathrm{HCO}_{3}{ }^{-}$is instantaneously formed by protonation of free $\mathrm{CO}_{3}{ }^{2-}$ according to Reaction (II). The rate-determining reaction of the second group is the kinetically controlled Reaction (IV). Here, $\mathrm{HCO}_{3}{ }^{-}$reacts back to $\mathrm{CO}_{2}$ and $\mathrm{OH}^{-} \cdot \mathrm{CO}_{2}$ then reacts very quickly to $\mathrm{MEACOO}^{-}$according to Reaction $(\mathrm{V})$ and $\mathrm{OH}^{-}$ reacts instantaneously with free $\mathrm{H}^{+}$back to $\mathrm{H}_{2} \mathrm{O}$ according to Reaction (I). As for the formation of $\mathrm{MEACOO}^{-}$, Figure 6 shows that more $\mathrm{MEACOO}^{-}$ is directly formed out of $\mathrm{MEA}$ and $\mathrm{HCO}_{3}{ }^{-}$according to Reaction (VI) than it is indirectly formed via Reactions $(\mathrm{IV})$ and $(\mathrm{V})$.

The forward reaction rate constants, $k_{\mathrm{f}, \mathrm{VI}}^{*}$, that were determined by the parameter estimation procedure described in Section 4 are listed for the different experiments in Table 2. The $95 \%$ confidence intervals of $k_{\mathrm{f}, \mathrm{VI}}^{*}$ reported in Table 2 are obtained from the parameter estimation procedure. This confidence interval takes only into account statistical errors and not systematic errors. We estimate the uncertainties of $k_{\mathrm{f}, \mathrm{VI}}^{*}$ to be much higher. On the one hand, as mentioned earlier, we estimate the accuracy of the thermostatization to be $\pm 1 \mathrm{~K}$, which directly influences $k_{\mathrm{f}, \mathrm{VI}}^{*}$. On the other hand, the NMR measurement itself is subject to uncertainties. All in all, we estimate the relative uncertainty of $k_{\mathrm{f}, \mathrm{VI}}^{*}$ to be $u_{\mathrm{r}}\left(k_{\mathrm{f}, \mathrm{VI}}^{*}\right)=0.1$. All experiments at $333 \mathrm{~K}$ and $313 \mathrm{~K}$ were conducted at least twice, as they are fast. The re- 
peatability is good, as can be seen from the data in the Excel spreadsheet in the Supplementary Material and from a comparison of the results for $k_{\mathrm{f}, \mathrm{VI}}^{*}$ in Table 2 for points, that were obtained at the same conditions.

Figure 7 shows the Arrhenius plot of the forward reaction rate constants, $k_{\mathrm{f}, \mathrm{VI}}^{*}$, of Reaction $(\mathrm{VI})$. The Arrhenius plot gives a straight line with only two values that deviate from the line. As the corresponding fits of the experimental data are good, it was decided not to exclude those values. A linear regression yielded an apparent activation energy of $E_{\mathrm{A}, \mathrm{VI}}=83.99 \mathrm{~kJ} \mathrm{~mol}^{-1}$ and a pre-exponential factor of $k_{\mathrm{f}, \mathrm{VI}}^{0, *}=8.92 \cdot 10^{10} \mathrm{~mol} \mathrm{~s}^{-1} \mathrm{l}^{-1}$.

The results from the present work were compared to literature data obtained by the group of Maeder in their experiments with salt-containing solutions [18, 19]. To enable a direct comparsion, the results from [18, 19] were converted as described in the Supplementary Material. The results from [18, 19] are included in Figure 7. The results from the present work agree well with those from McCann et al. [18]. The single result from Conway et al. [19] deviates both from our data and from that of McCann et al. [18]. The deviation of the single data point of Conway et al. [19] was probably due to the use of very diluted MEA $\left(0.025 \mathrm{~mol} \mathrm{l}^{-1}\right)$ and different $\mathrm{pH}$ value caused by different substances (Conway et al. [19]: $\mathrm{MEA} / \mathrm{H}_{2} \mathrm{O} / \mathrm{NaOH}+$ $\mathrm{H}_{2} \mathrm{O} / \mathrm{KHCO}_{3}$, McCann et al. [18]: $\mathrm{MEA} / \mathrm{H}_{2} \mathrm{O} / \mathrm{HCl}+\mathrm{H}_{2} \mathrm{O} / \mathrm{KHCO}_{3}$, this work: $\left.\mathrm{MEA} / \mathrm{H}_{2} \mathrm{O} / \mathrm{CO}_{2}+\mathrm{MEA} / \mathrm{H}_{2} \mathrm{O}\right)$.

The importance of Reaction (VI) for the design of a reactive absorption process was investigated in a process simulation study. Two cases were simulated with a rate-based model: The first case is a simulation of experiment A10 of Mangalapally and Hasse [43], who used the PCC pilot 
Table 2: Results of the estimation of the forward reaction rate constant $k_{\mathrm{f}, \mathrm{VI}}^{*}$ of Reaction (VI) according to Equation (11) with $95 \%$ confidence intervals at temperature $T$, $\mathrm{CO}_{2}$ loading $\alpha_{\mathrm{CO}_{2}}^{\mathrm{mix}}$ of the mixture, mass fraction of MEA $x_{\mathrm{MEA}}^{(\mathrm{m}), 0}$ in the unloaded stock solution, and $\mathrm{CO}_{2}$ loading $\alpha_{\mathrm{CO}_{2}}^{\mathrm{A}}$ of the $\mathrm{CO}_{2}$-loaded solution A. ${ }^{\mathrm{a}}$

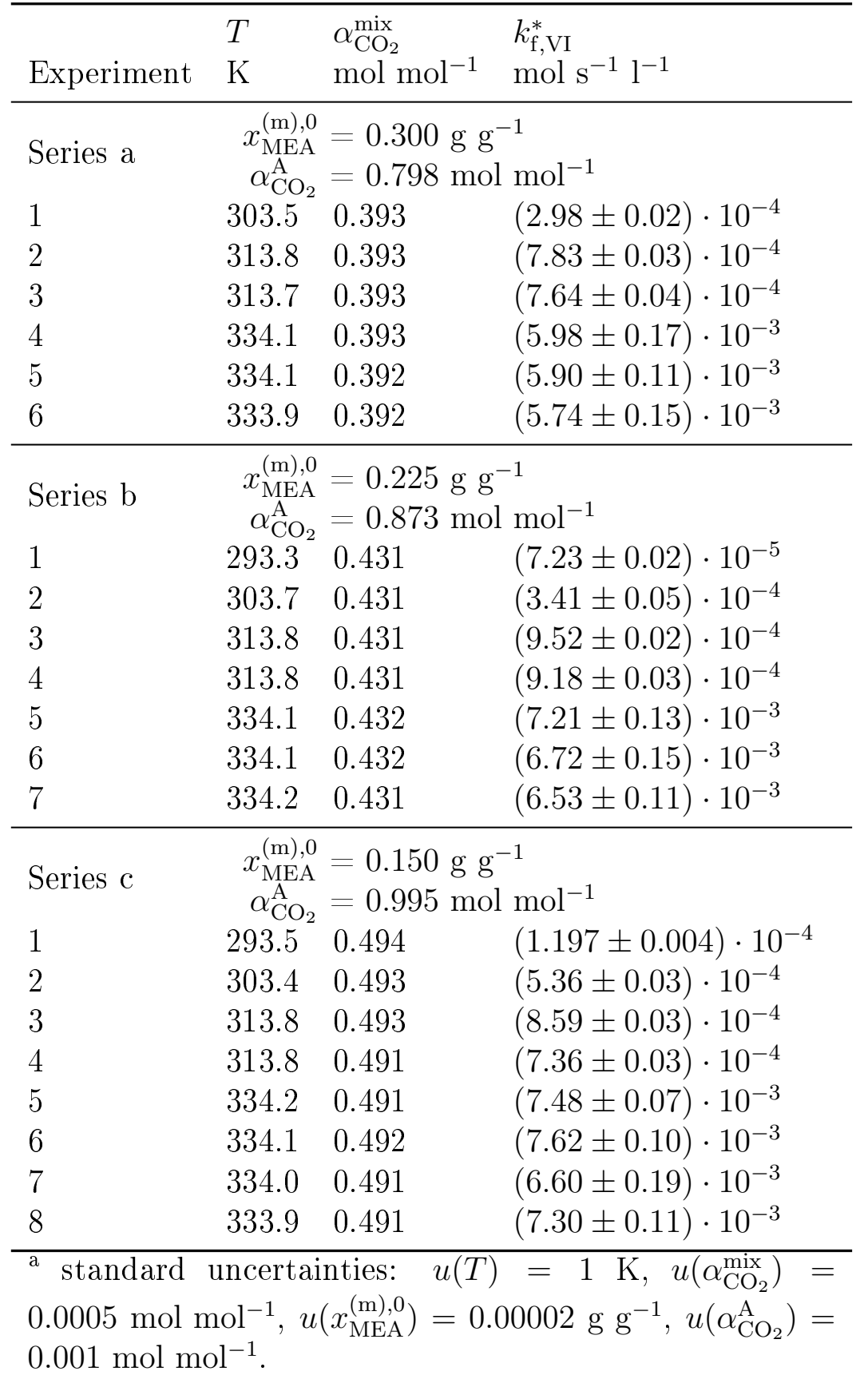


plant of our group to measure $\mathrm{CO}_{2}$ capture with aqueous MEA solution at ambient pressure. The second case, which is not based on real plant data but whose conditions can be found in the industry, is a simulation of $\mathrm{CO}_{2}$ capture with aqueous MEA solution at a pressure of 30 bar. In the first case, the gas (mole fraction of $\mathrm{CO}_{2}: y_{\mathrm{CO}_{2}}=0.147 \mathrm{~mol} \mathrm{~mol}^{-1}$, mass flow: $\dot{m}=79.3 \mathrm{~kg} \mathrm{~h}^{-1}$ ) flows upwards through a packed bed (packing type: Sulzer BX 500, packing height: $h=4.25 \mathrm{~m}$ ), countercurrent to a $\mathrm{CO}_{2}$-preloaded aqueous MEA solution $\left(\alpha_{\mathrm{CO}_{2}}=0.186 \mathrm{~mol} \mathrm{~mol}^{-1}, x_{\mathrm{MEA}}^{(\mathrm{m}), 0}=0.3 \mathrm{~g} \mathrm{~g}^{-1}\right.$, mass flow: $\dot{m}=200.2 \mathrm{~kg} \mathrm{~h}^{-1}$ ). In the second case, the gas (mole fraction of $\mathrm{CO}_{2}: y_{\mathrm{CO}_{2}}=0.183 \mathrm{~mol} \mathrm{~mol}{ }^{-1}$, mass flow: $\dot{m}=420.581 \mathrm{t} \mathrm{h}^{-1}$ ) also flows upwards through a packed bed (packing type: Koch-Glitsch IMTP 50, packing height: $h=10 \mathrm{~m})$, countercurrent to a $\mathrm{CO}_{2}$-pre-loaded aqueous MEA solution $\left(\alpha_{\mathrm{CO}_{2}}=0.186 \mathrm{~mol} \mathrm{~mol}^{-1}, x_{\mathrm{MEA}}^{(\mathrm{m}), 0}=0.3 \mathrm{~g} \mathrm{~g}^{-1}\right.$, mass flow: $\left.\dot{m}=1450.5 \mathrm{t} \mathrm{h}^{-1}\right)$. Both cases were simulated twice with the BASF in-house simulator CHEMASIM: once with the original model of von Harbou et al. [35] (i.e. Reactions $(\mathrm{I})-(\mathrm{V})$ ) and once with the extended model from the present work (i.e. Reactions (I)-(VI)). More details on the process simulation study are given in the Supplementary Material.

The simulation results of the first case (ambient pressure) are shown in Figure 8 , and the simulation results of the second case (pressure of 30 bar) are shown in Figure 9. For both cases, the column profile of the mole fraction, $y_{\mathrm{CO}_{2}}$, of $\mathrm{CO}_{2}$ in the gaseous phase, the column profile of the $\mathrm{CO}_{2}$ loading, $\alpha_{\mathrm{CO}_{2}}$, in the liquid phase, and the column profile of the mole fractions, $x_{i}$, of the major species in the liquid phase are depicted. In all column profiles, the results from the original model of von Harbou et al. [35] are plotted in dashed 
lines and the results from the extended model from the present work, which includes Reaction $(\sqrt{\mathrm{VI}})$, are plotted in solid lines. Symbols in the column profile of $\alpha_{\mathrm{CO}_{2}}$ of Figure 8 indicate experimental data of Mangalapally and Hasse [43].

For the first case, at ambient pressure, almost no influence of Reaction (VI) is observed. This finding is explained by the low partial pressure of $\mathrm{CO}_{2}$ in the bottom of the absorber that leads to a low $\mathrm{CO}_{2}$ loading in the liquid phase. At low $\mathrm{CO}_{2}$ loadings, the dissolved molecular $\mathrm{CO}_{2}$ reacts mainly via Reaction $(\mathrm{V})$ to $\mathrm{MEACOO}^{-}$and almost no $\mathrm{CO}_{2}$ reacts via Reaction (IV) to $\mathrm{HCO}_{3}^{-}$, so that Reaction (VI) is not important. Thus, in this regime the gas-liquid mass transfer of $\mathrm{CO}_{2}$ is enhanced only by Reaction $(\mathrm{V})$. Consequently, the model of von Harbou et al. [35] and the extended model from the present work describe the experimental data of Mangalapally and Hasse [43] equally well. The negligible influence of $\mathrm{HCO}_{3}{ }^{-}$on the overall absorption kinetics at low $\mathrm{CO}_{2}$ loadings coincide with the results of Putta et al. [31].

For the second case, at a pressure of 30 bar, a strong influence of Reaction (VI) is observed. The $\mathrm{CO}_{2}$ mole fraction in the purified gas stream is $500 \mathrm{ppm}$ when including and $1800 \mathrm{ppm}$ when excluding Reaction (VI). This finding is explained by the elevated pressure in conjunction with a high mole fraction of $\mathrm{CO}_{2}$ in the gaseous phase in the bottom of the absorber that leads to a high $\mathrm{CO}_{2}$ loading in the liquid phase. At high $\mathrm{CO}_{2}$ loadings, the dissolved molecular $\mathrm{CO}_{2}$ still reacts via Reaction $(\mathrm{V})$ to $\mathrm{MEACOO}^{-}$but substantial amounts of $\mathrm{CO}_{2}$ also react via Reaction (IV) to $\mathrm{HCO}_{3}{ }^{-}$. Thus, in this regime the gas-liquid mass transfer of $\mathrm{CO}_{2}$ is enhanced by Reaction (V) as 
well as by Reaction (IV). Reaction (VI) indirectly enhances the mass transfer even further by consuming $\mathrm{HCO}_{3}{ }^{-}$and, hence, increasing the reaction rate of Reaction (IV).

The study shows that for the development and scale-up of reactive absorption processes that are operated under elevated pressure, it matters whether that reaction is accounted for or not.

\section{Conclusion}

In this work, a new way of measuring the liquid phase reaction kinetics in systems of the type amine- $\mathrm{H}_{2} \mathrm{O}-\mathrm{CO}_{2}$ was developed and explored. It is based on an NMR flow probe with an integrated micromixer that was recently developed in our group [25, 27]. $\mathrm{A} \mathrm{CO}_{2}$-loaded aqueous amine solution is mixed with the corresponding unloaded solution which disturbs the chemical equilibrium. The reactions that lead to a new equilibrium state are monitored with ${ }^{1} \mathrm{H}$ NMR spectroscopy in stopped-flow mode. Reaction kinetics with half-lifes of reaction of more than about five seconds can be studied with this setup. It was used in the present work for investigating reaction kinetics in the system monoethanolamine $(\mathrm{MEA})-\mathrm{H}_{2} \mathrm{O}-\mathrm{CO}_{2}$. Predictions from a kinetic model of the reaction network in liquid mixtures of $\mathrm{MEA}, \mathrm{H}_{2} \mathrm{O}$, and $\mathrm{CO}_{2}$, which was developed in our group [35], were compared to the results. The predictions heavily underestimate the observed kinetics. This deviation is due to the fact that in the kinetic model [35] the reaction of MEA with $\mathrm{HCO}_{3}{ }^{-}$to $\mathrm{MEA}$ carbamate $\left(\mathrm{MEACOO}^{-}\right)$is not explicitly accounted for. The model was therefore extended with this reaction without making any other changes. The forward reaction rate constant was fitted to the experimental 
results from the present study. The temperature dependence of the forward reaction rate constant is described well by Arrhenius' law. The results of the extended model agree well with the kinetic data measured in the present work. The kinetics of the reaction of $\mathrm{MEA}$ with $\mathrm{HCO}_{3}{ }^{-}$to $\mathrm{MEACOO}^{-}$ had been studied before by the group of Maeder [18, 19]. However, the solutions that were investigated in these studies contained electrolytes, as carbonate salts were used for the preparation and not $\mathrm{CO}_{2}$ as in the present study. Nevertheless, the results from the present work agree well with those reported in [18]. The single data point reported in [19] deviates from both the results from the present study as well as those from [18]. This deviation is probably due to the fact that Conway et al. [19] investigated solutions with MEA concentrations and $\mathrm{pH}$ values that differ strongly from those that were studied in the present work.

It is known that the rate of absorption of $\mathrm{CO}_{2}$ into aqueous solutions of MEA is mainly influenced by the rate of reaction of $\mathrm{MEA}$ and $\mathrm{CO}_{2}$ [19]. However, the reaction of MEA with $\mathrm{HCO}_{3}{ }^{-}$gains importance when substantial amounts of bicarbonates are present in solution. This influence was demonstrated in the present work by simulations of two absorber columns that are operated at different pressures and, hence, in different ranges of $\mathrm{CO}_{2}$ loading. At low $\mathrm{CO}_{2}$ loadings (i.e. at ambient pressure), it does not matter whether the original model of [35] or the extended model from the present work this used. In contrast, significant differences are observed for the absorber operated at high $\mathrm{CO}_{2}$ loadings (i.e. at elevated pressure).

In reverse direction, the reaction studied here is the decomposition of $\mathrm{MEACOO}^{-}$[19]. Based on the results from the present study, also the ki- 
netics of this decomposition can now be assessed.

The experimental setup and procedure that were developed here can be used not only for studying kinetics in systems of the type amine- $\mathrm{H}_{2} \mathrm{O}-\mathrm{CO}_{2}$ but also for other systems where gaseous species react upon absorption in the liquid phase. As the procedure's main principle is the disturbing of the chemical equilibrium and the subsequent monitoring of the reactions that lead to a new equilibrium state, only reversible reactions can be investigated with this method. Also, the method is limited to studies of kinetics with half-lifes of reaction of more than about five seconds. The main advantage of the presented method is that only one single liquid phase is involved in the experiments. Hence, the information on the liquid phase reaction kinetics is not influenced by the gas-liquid mass transfer. Therefore, the new method is a useful tool to study complex reaction networks and to gather information essential for the development and scale-up of reactive gas-liquid processes.

\section{Acknowledgements}

We thank Ellen Steimers for her contributions to the experiments of the work.

\section{Funding}

This work was supported by the German Research Foundation (SFB/TRR $173 \operatorname{Spin}+\mathrm{X})$. 


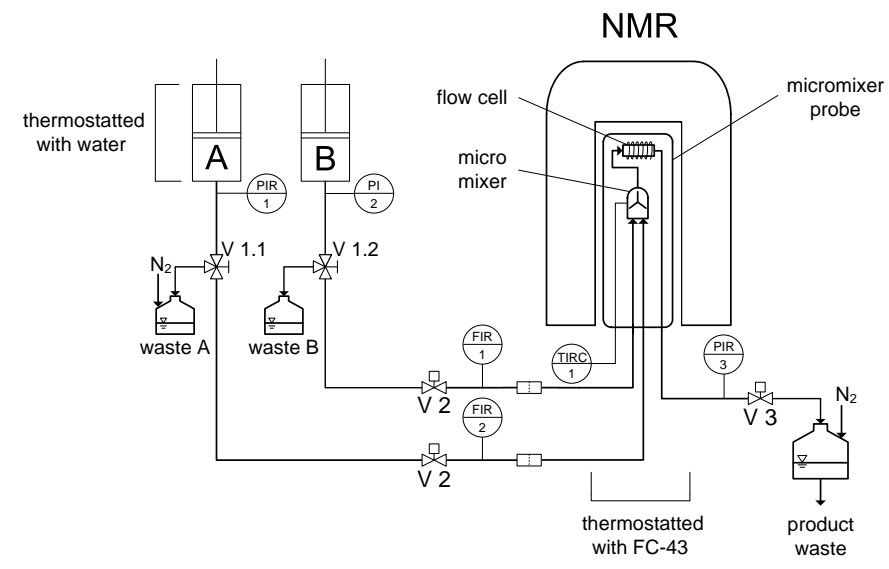

Figure 1: Process scheme of the experimental setup for stopped-flow rapid-mixing experiments. Valves V1.1 and V1.2 were used for the flushing of the pumps only. Both feed lines were connected to the 2-position, 6-port motorized valve V2.

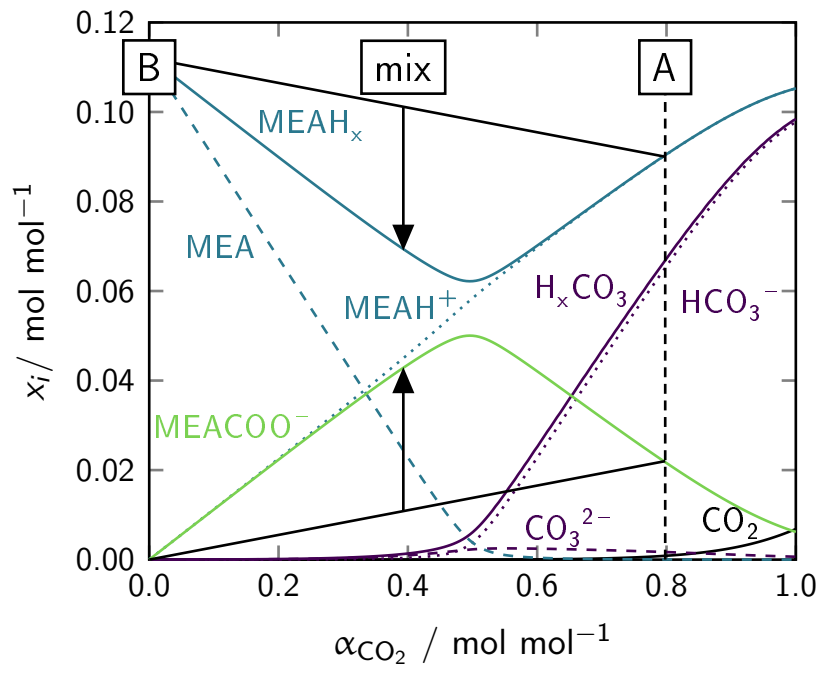

Figure 2: Composition of the liquid phase of the system $\mathrm{MEA}-\mathrm{H}_{2} \mathrm{O}-\mathrm{CO}_{2}$ in chemical equilibrium as a function of the $\mathrm{CO}_{2}$ loading, $\alpha_{\mathrm{CO}_{2}}$, for $x_{\mathrm{MEA}}^{(\mathrm{m}), 0}=0.3 \mathrm{~g} \mathrm{~g}^{-1}, T=293 \mathrm{~K}$. Curved lines: model of Wagner et al. [36]. Straight lines: visualization of mixing a $\mathrm{CO}_{2}$ loaded (A) with a $\mathrm{CO}_{2}$ free aqueous MEA solution (B) for the measurement series a. 

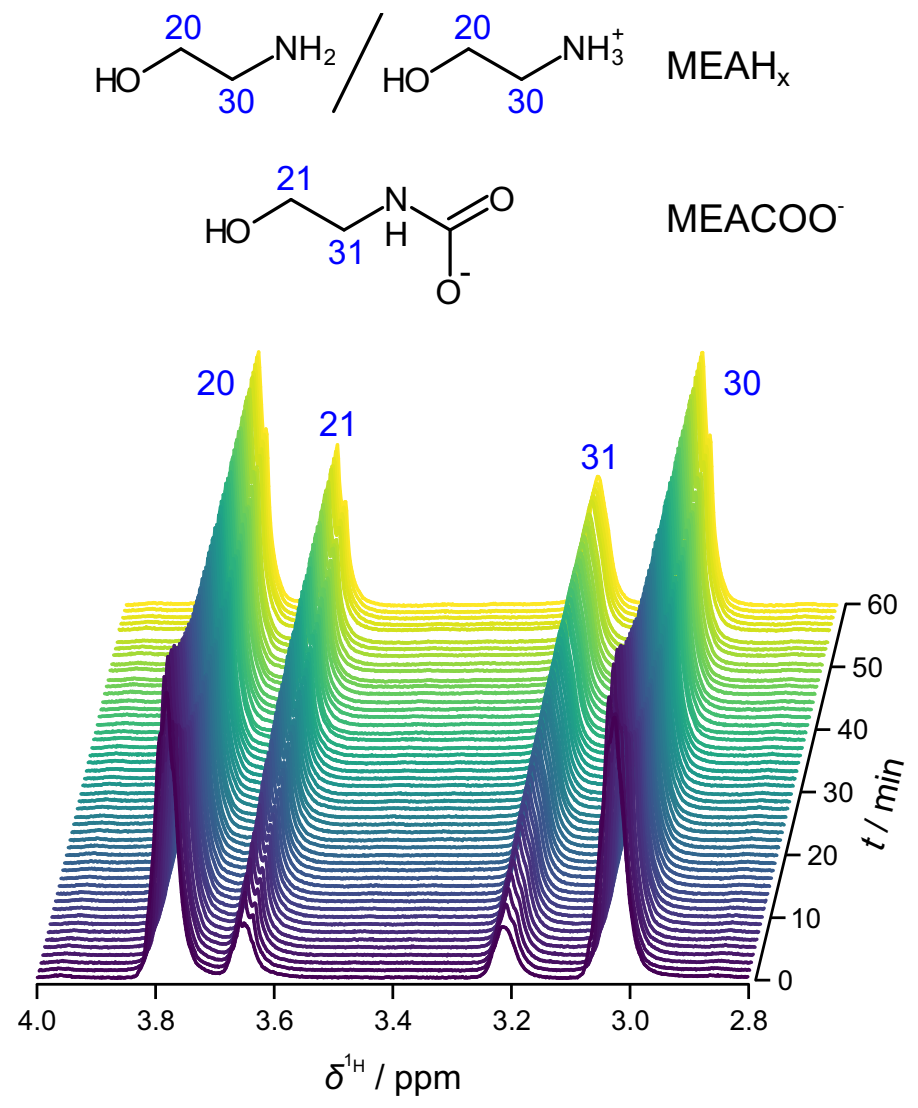

Figure 3: ${ }^{1} \mathrm{H}$ NMR spectra of the reacting MEA- $\mathrm{H}_{2} \mathrm{O}-\mathrm{CO}_{2}$ solution of Experiment a2 $\left(x_{\mathrm{MEA}}^{(\mathrm{m}), 0}=0.3 \mathrm{~g} \mathrm{~g}^{-1}, \alpha_{\mathrm{CO}_{2}}^{\mathrm{mix}}=0.393 \mathrm{~mol} \mathrm{~mol}^{-1}, T=313 \mathrm{~K}\right)$. 


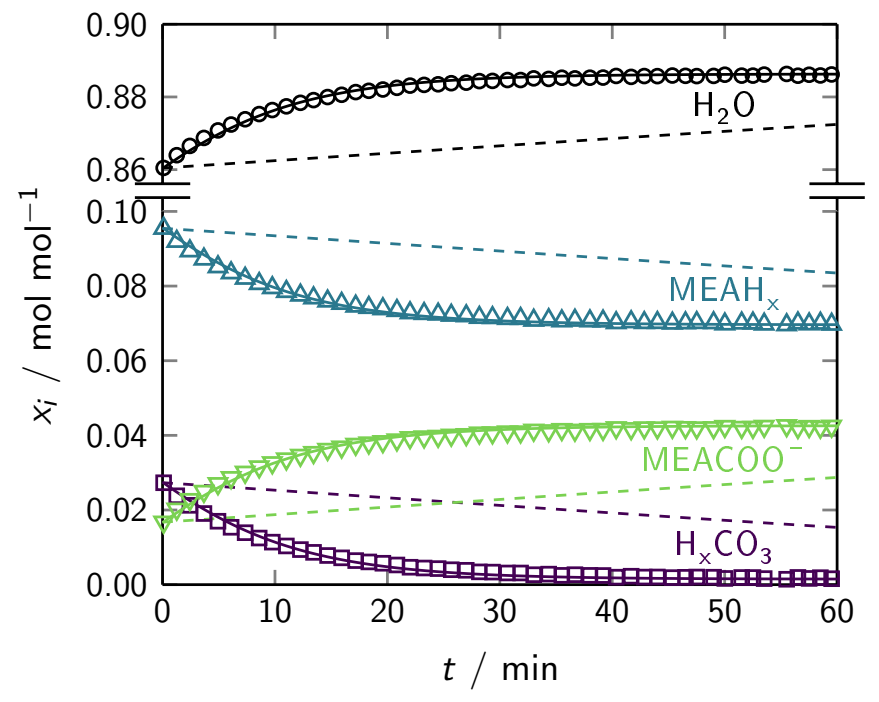

Figure 4: Composition of the reacting MEA- $\mathrm{H}_{2} \mathrm{O}-\mathrm{CO}_{2}$ solution in Experiment a2 $\left(x_{\mathrm{MEA}}^{(\mathrm{m}), 0}=0.3 \mathrm{~g} \mathrm{~g}^{-1}, \alpha_{\mathrm{CO}_{2}}^{\mathrm{mix}}=0.393 \mathrm{~mol} \mathrm{~mol}^{-1}, T=313 \mathrm{~K}\right)$ as a function of time. Symbols: experimental data from the present work. Dashed lines: model of von Harbou et al. [35]. Solid lines: model from the present work (von Harbou et al. [35] + Reaction (VI)). 

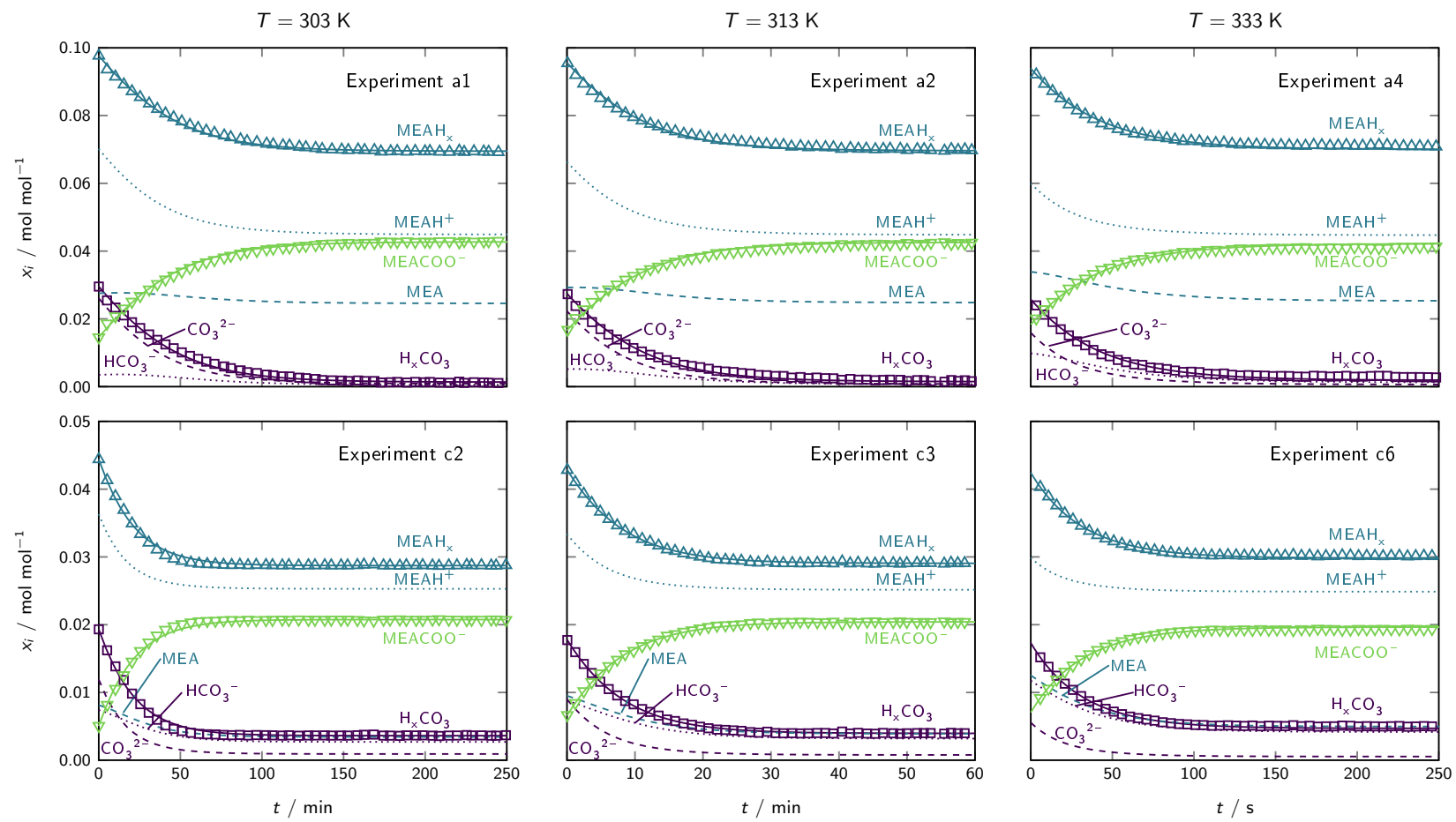

Figure 5: Composition of the reacting MEA- $\mathrm{H}_{2} \mathrm{O}-\mathrm{CO}_{2}$ solution as a function of time. Top row: Series a $\left(x_{\mathrm{MEA}}^{(\mathrm{m}), 0}=0.3 \mathrm{~g} \mathrm{~g}^{-1}, \alpha_{\mathrm{CO}_{2}}^{\mathrm{mix}}=0.39 \mathrm{~mol} \mathrm{~mol}^{-1}\right)$. Bottom row: Series c $\left(x_{\mathrm{MEA}}^{(\mathrm{m}), 0}=0.15 \mathrm{~g} \mathrm{~g}^{-1}, \alpha_{\mathrm{CO}_{2}}^{\mathrm{mix}}=0.49 \mathrm{~mol} \mathrm{~mol}^{-1}\right)$. Symbols: experimental data points from the present work. Lines: model from the present work. The model results of $x_{\mathrm{CO}_{2}}, x_{\mathrm{H}^{+}}$, and $x_{\mathrm{OH}^{-}}$are always below $0.001 \mathrm{~mol} \mathrm{~mol}^{-1}$ and are therefore not shown here. 


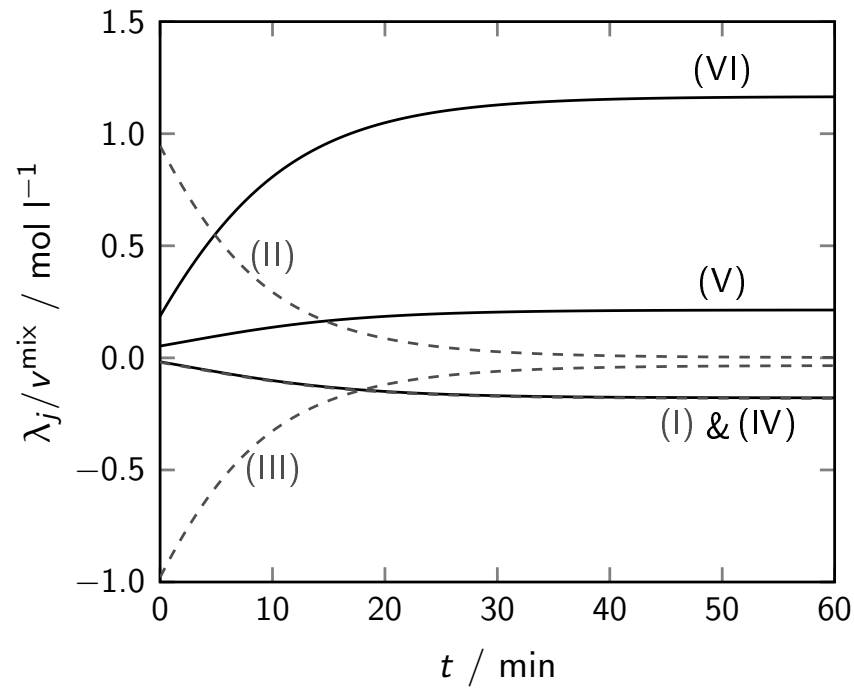

Figure 6: Extent of reaction divided by the molar volume of the reacting MEA- $\mathrm{H}_{2} \mathrm{O}-\mathrm{CO}_{2}$ solution in Experiment a2 $\left(x_{\mathrm{MEA}}^{(\mathrm{m}), 0}=0.3 \mathrm{~g} \mathrm{~g}^{-1}, \alpha_{\mathrm{CO}_{2}}^{\mathrm{mix}}=0.393 \mathrm{~mol} \mathrm{~mol}^{-1}, T=313 \mathrm{~K}\right)$ as a function of time. Results of the model from the present work. Solid lines: kinetically controlled equilibrium reactions. Dashed lines: instantaneous equilibrium reactions. 


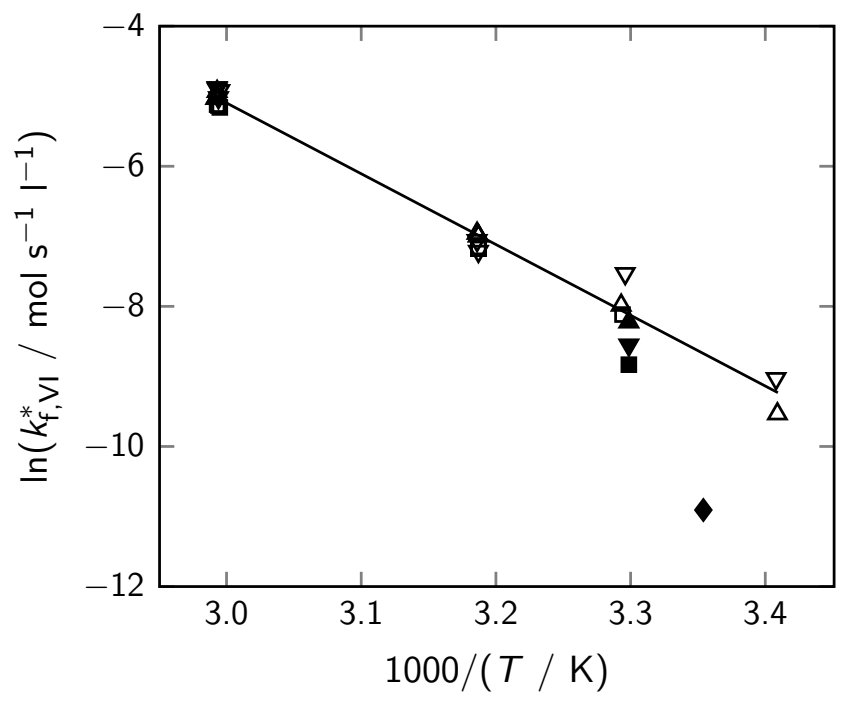

Figure 7: Arrhenius plot of the fitted forward reaction rate constants of Reaction (VI) according to Equation 11). $\square:$ Series a $\left(x_{\mathrm{MEA}}^{(\mathrm{m}), 0}=0.3 \mathrm{~g} \mathrm{~g}^{-1}, \alpha_{\mathrm{CO}_{2}}^{\mathrm{mix}}=0.39 \mathrm{~mol} \mathrm{~mol}^{-1}\right) . \Delta$ : Series b $\left(x_{\mathrm{MEA}}^{(\mathrm{m}), 0}=0.225 \mathrm{~g} \mathrm{~g}^{-1}, \alpha_{\mathrm{CO}_{2}}^{\operatorname{mix}}=0.43 \mathrm{~mol} \mathrm{~mol}^{-1}\right) . \nabla:$ Series c $\left(x_{\mathrm{MEA}}^{(\mathrm{m}), 0}=0.15 \mathrm{~g} \mathrm{~g}^{-1}\right.$, $\left.\alpha_{\mathrm{CO},}^{\mathrm{mix}}=0.49 \mathrm{~mol} \mathrm{~mol}^{-1}\right)$. Solid line: Arrhenius fit to the data of the present work. Results of McCann et al. [18] (their experiments a $\mathbf{\square}, \mathrm{b} \boldsymbol{\Lambda}, \mathrm{c} \boldsymbol{\nabla}$ ). $\downarrow$ : result of Conway et al. 19].
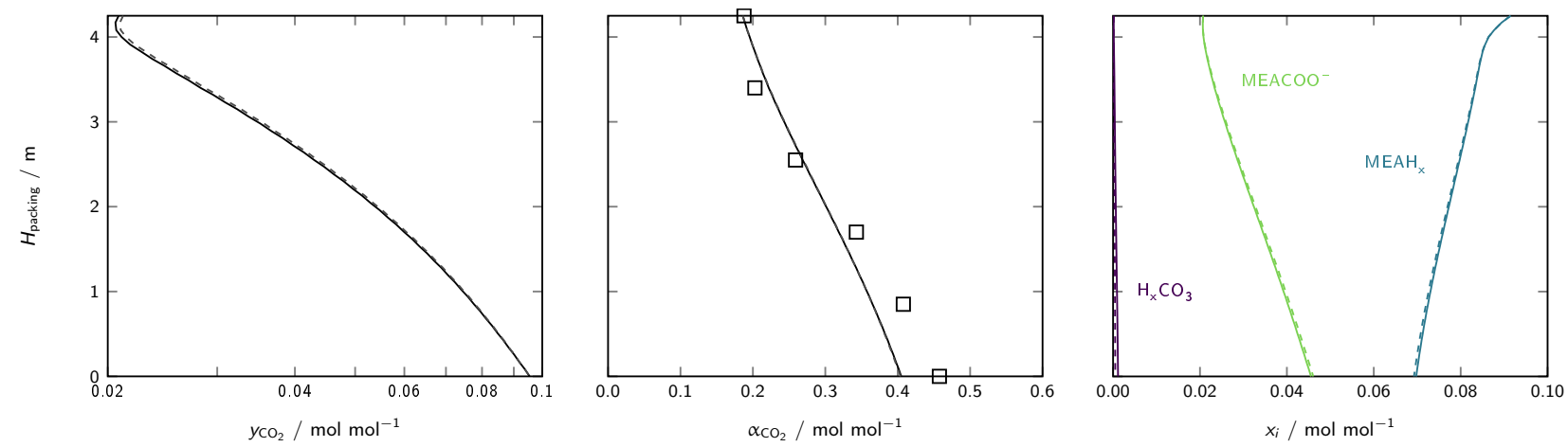

Figure 8: Absorber column profiles for the capture of $\mathrm{CO}_{2}$ with aqueous MEA solution. Simulation of experiment A10 of Mangalapally and Hasse [43, which was conducted at ambient pressure. Left: profiles of the mole fraction of $\mathrm{CO}_{2}$ in the gaseous phase. Middle: profiles of the $\mathrm{CO}_{2}$ loading in the liquid phase. Right: profiles of the mole fractions of the major species in the liquid phase. Dashed lines: model of von Harbou et al. [35]. Solid lines: model from the present work (von Harbou et al. [35] + Reaction (VI)). Symbols: experimental data of Mangalapally and Hasse 43 . 

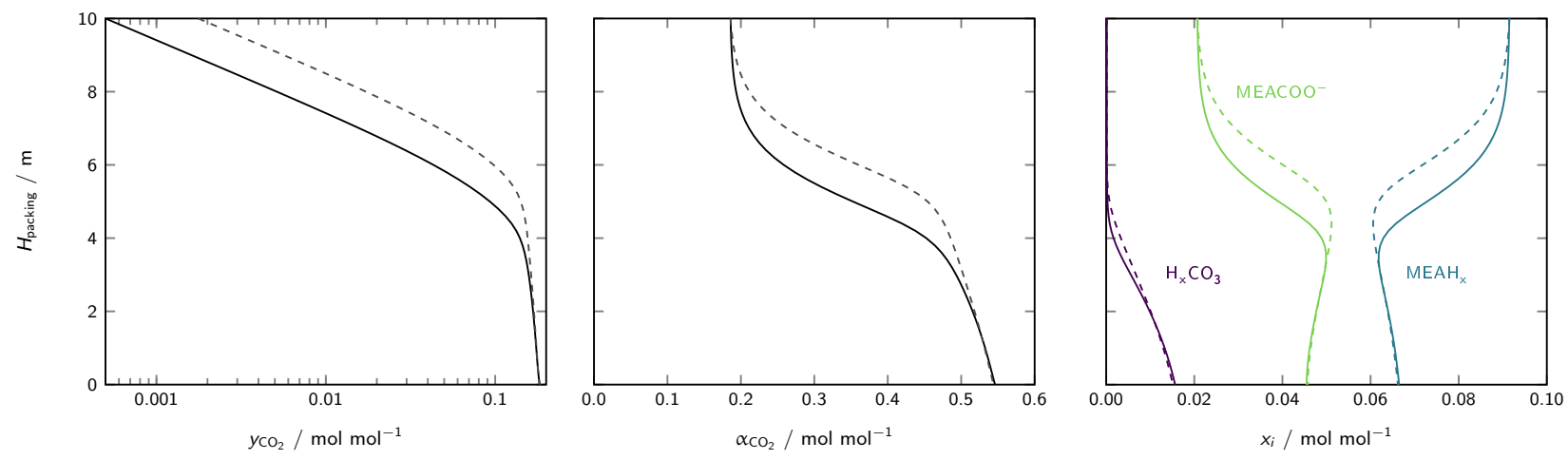

Figure 9: Absorber column profiles for the capture of $\mathrm{CO}_{2}$ with aqueous MEA solution. Simulation of a fictional high pressure case $(p=30$ bar $)$. Left: profiles of the mole fraction of $\mathrm{CO}_{2}$ in the gaseous phase. Middle: profiles of the $\mathrm{CO}_{2}$ loading in the liquid phase. Right: profiles of the mole fractions of the major species in the liquid phase. Dashed lines: model of von Harbou et al. [35. Solid lines: model from the present work (von Harbou et al. [35] + Reaction (VI)). 


\section{Appendix A. Supplementary Material}

Supplementary Material associated with this article can be found in the online version, at: http://dx.doi.org/10.1016/j.cej.xxxx-xx-xxx.

\section{References}

[1] F. Griolet, J. Lieto, G. Astarita, Containment of phosgene accidental release-Kinetics of phosgene absorption in sodium hydroxide solution, Chem. Eng. Sci. 51 (1996) 3213-3221. doi:10.1016/0009-2509(95) 00373-8.

[2] O. Yildirim, A. A. Kiss, N. Hüser, K. Leßsmann, E. Y. Kenig, Reactive absorption in chemical process industry: A review on current activities, Chem. Eng. J. 213 (2012) 371-391. doi:10.1016/j.cej.2012.09.121.

[3] P.-F. Biard, T. T. Dang, A. Couvert, Determination by reactive absorption of the rate constant of the ozone reaction with the hydroperoxide anion, Chem. Eng. Res. Des. 127 (2017) 62-71. doi:10.1016/j.cherd. 2017.09 .004 .

[4] H. Hasse, I. von Harbou, Post Combustion Capture, in: Carbon Capture and Storage in Europe, EASAC Policy Report 20, German National Academy of Sciences Leopoldina, Halle (Saale), 2013.

[5] S. H. Kim, K. H. Kim, S. H. Hong, Carbon Dioxide Capture and Use: Organic Synthesis Using Carbon Dioxide from Exhaust Gas, Angew. Chem. Int. Ed. 53 (2014) 771-774. doi:10.1002/anie.201308341. 
[6] I. Tönnies, H. P. Mangalapally, H. Hasse, Sensitivity study for the ratebased simulation of the reactive absorption of CO2, Energy Procedia 4 (2011) 533-540. doi:10.1016/j .egypro.2011.01.085.

[7] X. Yang, R. J. Rees, W. Conway, G. Puxty, Q. Yang, D. A. Winkler, Computational Modeling and Simulation of CO2 Capture by Aqueous Amines, Chem. Rev. 117 (2017) 9524-9593. doi:10.1021/acs . chemrev. $6 \mathrm{~b} 00662$.

[8] A. Aboudheir, P. Tontiwachwuthikul, A. Chakma, R. Idem, Kinetics of the reactive absorption of carbon dioxide in high CO2-loaded, concentrated aqueous monoethanolamine solutions, Chem. Eng. Sci. 58 (2003) 5195-5210. doi: $10.1016 /$ j.ces .2003.08.014.

[9] M. Edali, A. Aboudheir, R. Idem, Kinetics of carbon dioxide absorption into mixed aqueous solutions of MDEA and MEA using a laminar jet apparatus and a numerically solved 2D absorption rate/kinetics model, Int. J. Greenh. Gas Con. 3 (2009) 550-560. doi:10.1016/j.ijggc. 2009. 04.006 .

[10] G. Puxty, R. Rowland, M. Attalla, Comparison of the rate of CO2 absorption into aqueous ammonia and monoethanolamine, Chem. Eng. Sci. 65 (2010) 915-922. doi:10.1016/j.ces.2009.09.042.

[11] R. E. Dugas, G. T. Rochelle, CO2 Absorption Rate into Concentrated Aqueous Monoethanolamine and Piperazine, J. Chem. Eng. Data 56 (2011) 2187-2195. doi:10.1021/je101234t. 
[12] X. Luo, A. Hartono, S. Hussain, H. F. Svendsen, Mass transfer and kinetics of carbon dioxide absorption into loaded aqueous monoethanolamine solutions, Chem. Eng. Sci. 123 (2015) 57-69. doi:10. $1016 /$ j.ces . 2014.10.013.

[13] J. G. M.-S. Monteiro, S. Hussain, H. Majeed, E. O. Mba, A. Hartono, H. Knuutila, H. F. Svendsen, Kinetics of $\mathrm{CO} 2$ absorption by aqueous 3-(methylamino)propylamine solutions: Experimental results and modeling, AIChE J. 60 (2014) 3792-3803. doi:10.1002/aic.14546.

[14] S. S. Laddha, J. M. Diaz, P. V. Danckwerts, The N2O analogy: The solubilities of $\mathrm{CO} 2$ and $\mathrm{N} 2 \mathrm{O}$ in aqueous solutions of organic compounds, Chem. Eng. Sci. 36 (1981) 228-229. doi:10.1016/ 0009-2509(81)80074-7.

[15] E. Sada, H. Kumazawa, Z. Q. Han, H. Matsuyama, Chemical kinetics of the reaction of carbon dioxide with ethanolamines in nonaqueous solvents, AIChE J. 31 (1985) 1297-1303. doi:10.1002/aic.690310808.

[16] D. E. Penny, T. J. Ritter, Kinetic study of the reaction between carbon dioxide and primary amines, J. Chem. Soc. Faraday Trans. 179 (1983) 2103-2109. doi:10.1039/F19837902103.

[17] D. Barth, C. Tondre, J. J. Delpuech, Stopped-flow investigations of the reaction kinetics of carbon dioxide with some primary and secondary alkanolamines in aqueous solutions, Int. J. Chem. Kinet. 18 (1986) 445457. doi:10.1002/kin.550180404. 
[18] N. McCann, D. Phan, X. Wang, W. Conway, R. Burns, M. Attalla, G. Puxty, M. Maeder, Kinetics and Mechanism of Carbamate Formation from CO2(aq), Carbonate Species, and Monoethanolamine in Aqueous Solution, J. Phys. Chem. A 113 (2009) 5022-5029. doi:10. 1021/jp810564z.

[19] W. Conway, X. Wang, D. Fernandes, R. Burns, G. Lawrance, G. Puxty, M. Maeder, Comprehensive Kinetic and Thermodynamic Study of the Reactions of $\mathrm{CO} 2(\mathrm{aq})$ and $\mathrm{HCO} 3-$ with Monoethanolamine (MEA) in Aqueous Solution, J. Phys. Chem. A 115 (2011) 14340-14349. doi:10. 1021/jp2081462.

[20] J. E. Crooks, J. P. Donnellan, Kinetics and mechanism of the reaction between carbon dioxide and amines in aqueous solution, J. Chem. Soc., Perkin Trans. 20 (1989) 331-333. doi:10.1039/P29890000331.

[21] E. Alper, Reaction mechanism and kinetics of aqueous solutions of 2amino-2-methyl-1-propanol and carbon dioxide, Ind. Eng. Chem. Res. 29 (1990) 1725-1728. doi:10.1021/ie00104a023.

[22] S. H. Ali, Kinetics of the reaction of carbon dioxide with blends of amines in aqueous media using the stopped-flow technique, Int. J. Chem. Kinet. 37 (2005) 391-405. doi:10.1002/kin.20059.

[23] H. Hikita, S. Asai, H. Ishikawa, M. Honda, The kinetics of reactions of carbon dioxide with monoethanolamine, diethanolamine and triethanolamine by a rapid mixing method, Chem. Eng. J. Biochem. Eng. J. 13 (1977) 7-12. doi:10.1016/0300-9467(77)80002-6. 
[24] L. Kucka, E. Y. Kenig, A. Górak, Kinetics of the Gas-Liquid Reaction between Carbon Dioxide and Hydroxide Ions, Ind. Eng. Chem. Res. 41 (2002) 5952-5957. doi:10.1021/ie020452f.

[25] A. Brächer, S. Hoch, K. Albert, H. J. Kost, B. Werner, E. von Harbou, H. Hasse, Thermostatted micro-reactor NMR probe head for monitoring fast reactions, J. Magn. Reson. 242 (2014) 155-161. doi:10.1016/j . jmr. 2014.02 .013 .

[26] A. Scheithauer, A. Brächer, T. Grützner, D. Zollinger, W. R. Thiel, E. von Harbou, H. Hasse, Online 1H NMR Spectroscopic Study of the Reaction Kinetics in Mixtures of Acetaldehyde and Water Using a New Microreactor Probe Head, Ind. Eng. Chem. Res. 53 (2014) 17589-17596. doi:10.1021/ie5033556.

[27] A. Brächer, R. Behrens, E. von Harbou, H. Hasse, Application of a new micro-reactor $1 \mathrm{H}$ NMR probe head for quantitative analysis of fast esterification reactions, Chem. Eng. J. 306 (2016) 413-421. doi:10.1016/ j.cej.2016.07.045.

[28] E. von Harbou, R. Behrens, J. Berje, A. Brächer, H. Hasse, Studying Fast Reaction Kinetics with Online NMR Spectroscopy, Chem. Ing. Tech. 89 (2017) 369-378. doi:10.1002/cite.201600068.

[29] P. V. Kortunov, M. Siskin, L. S. Baugh, D. C. Calabro, In Situ Nuclear Magnetic Resonance Mechanistic Studies of Carbon Dioxide Reactions with Liquid Amines in Aqueous Systems: New Insights on Car- 
bon Capture Reaction Pathways, Energy Fuels 29 (2015) 5919-5939. doi:10.1021/acs.energyfuels.5b00850.

[30] P. Luis, Use of monoethanolamine (MEA) for CO2 capture in a global scenario: Consequences and alternatives, Desalination 380 (2016) 93-99. doi:10.1016/j.desal.2015.08.004.

[31] K. R. Putta, D. D. D. Pinto, H. F. Svendsen, H. K. Knuutila, CO2 absorption into loaded aqueous MEA solutions: Kinetics assessment using penetration theory, Int. J. Greenh. Gas Con. 53 (2016) 338-353. doi:10.1016/j.ijggc.2016.08.009.

[32] P. D. Vaidya, E. Y. Kenig, Gas-Liquid Reaction Kinetics: A Review of Determination Methods, Chem. Eng. Commun. 194 (2007) 1543-1565. doi:10.1080/00986440701518314.

[33] P. D. Vaidya, E. Y. Kenig, CO2-Alkanolamine Reaction Kinetics: A Review of Recent Studies, Chem. Eng. Technol. 30 (2007) 1467-1474. doi:10.1002/ceat.200700268.

[34] Y. Matsuzaki, H. Yamada, F. A. Chowdhury, T. Higashii, M. Onoda, Ab Initio Study of CO2 Capture Mechanisms in Aqueous Monoethanolamine: Reaction Pathways for the Direct Interconversion of Carbamate and Bicarbonate, J. Phys. Chem. A 117 (2013) 9274-9281. doi:10.1021/jp406636a.

[35] I. von Harbou, M. Imle, H. Hasse, Modeling and simulation of reactive absorption of $\mathrm{CO} 2$ with MEA: Results for four different packings on two 
different scales, Chem. Eng. Sci. 105 (2014) 179-190. doi:10.1016/j. ces.2013.11.005.

[36] M. Wagner, I. von Harbou, J. Kim, I. Ermatchkova, G. Maurer, H. Hasse, Solubility of Carbon Dioxide in Aqueous Solutions of Monoethanolamine in the Low and High Gas Loading Regions, J. Chem. Eng. Data 58 (2013) 883-895. doi:10.1021/je301030z.

[37] V. P. Talzi, S. V. Ignashin, NMR Study of Decomposition of Monoethanolamine under Conditions of Industrial Gas Treatment, Russ. J. Appl. Chem. 75 (2002) 80-85. doi:10.1023/A:1015573008284.

[38] R. Behrens, E. Kessler, K. Münnemann, H. Hasse, E. von Harbou, Monoalkylcarbonate formation in the system monoethanolamine--water-carbon dioxide, Fluid Phase Equilib. 486 (2019) 98-105. doi:10.1016/j.fluid.2018.12.031.

[39] C. Ammann, P. Meier, A. Merbach, A simple multinuclear NMR thermometer, J. Magn. Reson. 46 (1982) 319-321. doi:10.1016/ 0022-2364(82)90147-0.

[40] P. T. Callaghan, Principles of Nuclear Magnetic Resonance Microscopy, Clarendon Press, Oxford, 1993.

[41] K. S. Pitzer, Thermodynamics of electrolytes. I. Theoretical basis and general equations, J. Phys. Chem. 77 (1973) 268-277. doi:10.1021/ j100621a026.

[42] K. S. Pitzer, Activity Coefficients in Electrolyte Solutions, CRC Press, Boca Raton, FL, 1991. 
[43] H. P. Mangalapally, H. Hasse, Pilot plant study of post-combustion carbon dioxide capture by reactive absorption: Methodology, comparison of different structured packings, and comprehensive results for monoethanolamine, Chem. Eng. Res. Des. 89 (2011) 1216-1228. doi:10.1016/j.cherd.2011.01.013. 


\section{Appendix B. Graphical TOC Entry}

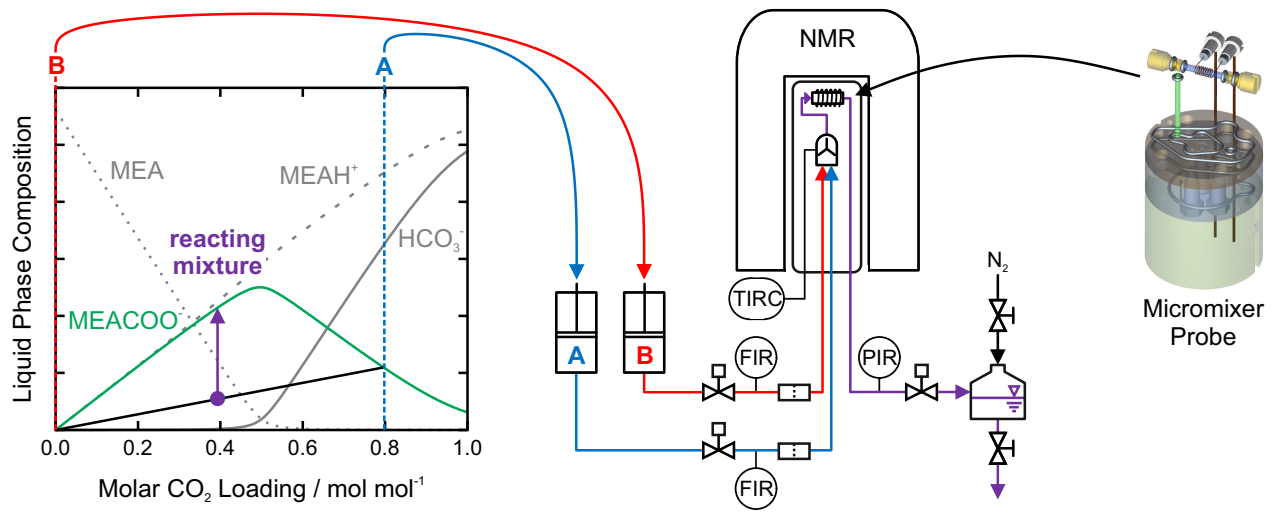

